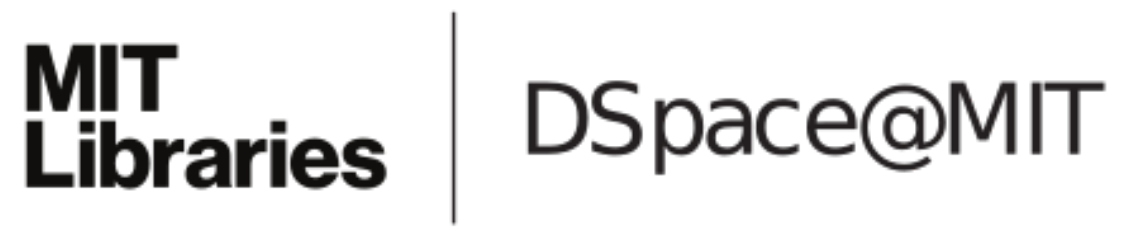

\author{
MIT Open Access Articles
}

\section{Adopting a Label: Heterogeneity in the Economic Consequences Around IAS/IFRS Adoptions}

The MIT Faculty has made this article openly available. Please share how this access benefits you. Your story matters.

Citation: DASKE, HOLGER, LUZI HAIL, CHRISTIAN LEUZ, and RODRIGO VERDI. "Adopting a Label: Heterogeneity in the Economic Consequences Around IAS/IFRS Adoptions." Journal of Accounting Research 51, no. 3 (June 2013): 495-547.

As Published: http://dx.doi.org/10.1111/1475-679x.12005

Publisher: Wiley Blackwell

Persistent URL: http://hdl.handle.net/1721.1/88143

Version: Author's final manuscript: final author's manuscript post peer review, without publisher's formatting or copy editing

Terms of use: Creative Commons Attribution-Noncommercial-Share Alike 


\title{
Adopting a Label: Heterogeneity in the Economic Consequences around IAS/IFRS Adoptions*
}

\author{
Holger Daske \\ University of Mannheim \\ Luzi Hail \\ The Wharton School, University of Pennsylvania \\ Christian Leuz \\ The University of Chicago Booth School of Business and NBER \\ Rodrigo Verdi \\ Sloan School of Management, MIT
}

Forthcoming in Journal of Accounting Research, 2013

\begin{abstract}
This study examines liquidity and cost of capital effects around voluntary and mandatory IAS/IFRS adoptions. In contrast to prior work, we focus on the firm-level heterogeneity in the economic consequences, recognizing that firms have considerable discretion in how they implement the new standards. Some firms may make very few changes and adopt IAS/IFRS more in name, while for others the change in standards could be part of a strategy to increase their commitment to transparency. To test these predictions, we classify firms into 'label' and 'serious' adopters using firm-level changes in reporting incentives, actual reporting behavior, and the external reporting environment around the switch to IAS/IFRS. We analyze whether capitalmarket effects are different across 'serious' and 'label' firms. While on average liquidity and costs of capital often do not change around voluntary IAS/IFRS adoptions, we find considerable heterogeneity: 'Serious' adoptions are associated with an increase in liquidity and a decline in cost of capital, whereas 'label' adoptions are not. We obtain similar results when classifying firms around mandatory IFRS adoption. Our findings imply that we have to exercise caution when interpreting capital-market effects around IAS/IFRS adoption as they also reflect changes in reporting incentives or broader changes in firms' reporting strategies, and not just the standards.
\end{abstract}

JEL classification: G14, G15, G30, K22, M41, M42

Key Words: International accounting, Reporting incentives, IAS, U.S. GAAP, Disclosure, Cost of equity, IFRS implementation

* Accepted by Douglas Skinner. We appreciate the helpful comments of an anonymous referee, Ray Ball, Hans Christensen, Joachim Gassen, Günther Gebhardt, Bob Holthausen, Bjorn Jorgensen, Peter Wysocki, Steve Young, and workshop participants at the 2007 Utah Winter Accounting Conference, 2007 Harvard Business School IMO Conference, 2007 Global Issues in Accounting Conference, 2007 Journal of Accounting, Auditing and Finance Conference, 2008 AAA Annual Meeting, University of Chicago, INSEAD, Lancaster University, University of Lugano, University of Mannheim, Massachusetts Institute of Technology, University of Missouri, and New York University. We thank Eric Blouin, Emily Goergen, Wannia Hu, Yuji Maruyama, Anindya Mishra, Michael Sall, Caleb Smith, Richie Wan, and Kai Wright for their excellent research assistance. The dataset of voluntary IAS reporting is available for download here: http://research.chicagobooth.edu/arc/journal/onlineappendices.aspx. 


\section{Introduction}

Over the last number of years the adoption of International Financial Reporting Standards (IFRS) or, before that, International Accounting Standards (IAS) has gained considerable momentum around the world. ${ }^{1}$ Over 100 countries require or permit the use of IFRS for financial reporting purposes, and several more are considering a mandate or at least to give firms an option to report under IFRS ( $\underline{\text { www.iasplus.com})}$. Even before the IFRS mandate, many firms have voluntarily adopted IAS. An important issue for the literature analyzing capital-market outcomes around IAS and IFRS adoptions is whether the observed consequences can be attributed to the change in standards itself, and hence can be labeled IAS or IFRS effects.

To highlight the difficulties in isolating such effects, we examine cross-sectional differences in capital-market outcomes around IAS/IFRS adoptions and the role of firm-level reporting incentives in explaining them. We show that a simple partitioning based on changes in firm-level reporting incentives around IAS/IFRS adoptions has significant explanatory power for the direction and magnitude of the observed capital-market outcomes. The evidence is consistent with pervasive selection effects, particularly for voluntary adoptions, and cautions us to interpret observed capital-market outcomes as a response to the change in standards alone. The evidence also questions the extent to which a switch to IAS/IFRS by itself (without any other changes) represents a commitment to a certain level of transparency.

For the most part, our analyses center on voluntary IAS adoptions. We do so for three reasons. First, our research design relies crucially on having sufficient variation in the underlying motives for IAS adoption to illustrate the selection issue. In this regard, studying voluntary adopters helps

See, e.g., Barth [2008] and Hail, Leuz, and Wysocki [2010]. In 2001, IAS were renamed to IFRS. In this paper, we use the two terms interchangeably, but primarily refer to IAS as our sample period goes back as far as 1990 . 
to increase the power of the tests. Yet, as we demonstrate later in the paper, reporting incentives also play a role around mandatory IFRS adoption, for instance, in determining whether firms resist changing their reporting practices. Second, voluntary IAS adoptions are not as clustered in time as mandatory adoptions but rather spread over multiple periods (from 1990 to 2005 in our sample). This feature makes it easier to eliminate the effects of unrelated economic shocks and institutional changes. Third, understanding the effects around voluntary adoptions is useful even in times when IFRS reporting is mandatory in many countries. For instance, firms that adopted IAS/IFRS voluntarily can serve as an important benchmark in studies that seek to identify the effects of mandatory IFRS reporting (e.g., Christensen, Hail, and Leuz [2012]). Furthermore, voluntary adoption is relevant to private firms that in most jurisdictions are not subject to the IFRS mandate and to firms with the option to adopt IFRS in countries not yet imposing a mandate.

Our main hypothesis is that the observed economic consequences around IAS adoptions depend on management's reporting incentives, including the underlying motivations for the accounting change, rather than the change in accounting standards per se. As a result we expect predictable heterogeneity in outcomes across firms. In particular, one frequently voiced concern is that some firms adopt IAS merely in name without making material changes to their reporting policies (e.g., Ball [2001], [2006]). We refer to these firms as 'label adopters'. Firms may also adopt IAS as part of a broader strategy to increase their commitment to transparency. We refer to these firms as 'serious adopters' meaning that they are 'serious' about the change in their reporting strategy (which includes but is not necessarily limited to IAS adoption). Our study is designed to identify and examine such differences across firms. Provided that investors can 
differentiate between 'serious' and 'label' firms, we should observe differential capital-market effects, e.g., in market liquidity and cost of capital.

To conduct our analysis, we construct a large panel of voluntary IAS adoptions from 1990 to 2005 across 30 countries. We identify voluntary IAS adoptions based on accounting standards data in Worldscope, Global Vantage, and an extensive hand-collection of more than 20,000 annual reports. We create an IAS reporting panel, which allows us to provide descriptive evidence on the adoption trends around the world as well as on firms' individual adoption strategies (see the Appendix). As expected, the number of firms reporting under IAS steadily increases over the years. In addition, there is substantial variation in the frequency of voluntary IAS adoptions across countries.

We begin our tests by analyzing whether voluntary IAS reporting, on average, is associated with higher market liquidity and a lower cost of capital relative to local GAAP firms, and relative to firms' own pre-IAS histories. We examine three measures of economic outcomes, namely the price impact of trades (Amihud [2002]), the percentage bid-ask spread, and the implied cost of capital. Using these variables (and several others in the sensitivity analyses), we find little evidence that voluntary IAS (or U.S. GAAP) reporting has beneficial capital-market effects. To benchmark the findings, we show that proxies indicating stronger firm-level reporting incentives (measured in levels) as well as U.S. cross-listings, which have been shown to represent a credible commitment to more transparency (e.g., Hail and Leuz [2009]), are associated with higher market liquidity and a lower cost of capital. Both benchmark findings make it unlikely that measurement error in the dependent variables or lack of power are responsible for the weak average effects around voluntary IAS adoptions. 
Next, we analyze firm-level heterogeneity in the capital-market effects around voluntary IAS adoptions. The idea behind these tests is to illustrate that markets respond positively to changes in firms' economics that lead to improvements in management's reporting incentives around IAS adoptions, but not to all IAS adoptions. This, in turn, calls into question whether the capital market effects are attributable to IAS reporting per se. We use three proxies to identify major changes in firm-level reporting incentives around IAS adoptions. Our first proxy is input-based and focuses directly on firm characteristics that shape management's reporting incentives. Specifically, we expect managers in firms that are larger, more profitable, more international, have larger financing needs, larger growth opportunities, and more dispersed ownership structures to have stronger incentives for transparent financial reporting. We use factor analysis to summarize the incentive effects from these firm attributes and extract a single factor (with consistent loadings). Our second proxy is output-based and focuses on firms' reporting behavior. It is built on the idea that actual reporting changes are ultimately driven by changes in the underlying incentives. Following Leuz, Nanda, and Wysocki [2003], we use the magnitude of accruals relative to the cash flow from operations as a simple characterization of reporting behavior and earnings informativeness. Accrual-based proxies for earnings quality have been contentious in the literature (e.g., Dechow, Ge, and Schrand [2010]). They could also be spuriously affected in our stetting due to the switch in accounting standards. Thus, we use a third proxy that does not rely on accounting information. Namely, we capture changes in the external reporting environment using the number of analysts following a firm. The idea is that scrutiny by analysts and markets also shapes management's reporting incentives. For each of the three 
proxies, we compute the changes around IAS adoptions, and use the distribution of the changes to split the sample into 'serious' and 'label' firms. ${ }^{2}$

The cross-sectional analyses provide the following results: first, we show that firms exhibit substantial (positive and negative) variation in the three proxies for changes in reporting incentives around IAS adoptions. Second, we show that 'serious' adopters (i.e., firms with above median changes in reporting incentives) experience an increase in market liquidity and a decline in the costs of capital relative to 'label' adopters. The results are statistically and economically significant and similar across partitioning variables. Compared to local GAAP firms, the net effect on market liquidity is also positive and economically significant, consistent with the notion that serious adopters increase their commitment to transparency. The net effect on cost of capital is less robust and generally close to zero, except when we split by the reporting incentives factor, in which case we find a significant decrease in the cost of capital. Similarly, we find evidence that the net effect on Tobin's q is significantly positive, as predicted, for serious adopters when using the change in the reporting incentives factor.

Finally, we show that the three partitions also explain firm-level heterogeneity in the effects around mandatory IFRS adoptions. Thus, the reporting incentive results carry over to mandatory accounting changes. These tests address an important concern: given that our sample spreads over many years during which IAS/IFRS have evolved substantially, the results could reflect heterogeneity in what constitutes an IAS adoption or in the standards themselves, rather than

2 The construction of our split variables and the focus on changes allows for the possibility that firms with strong reporting incentives already provide high-quality reports under local GAAP. Thus, 'label' adopters are not necessarily firms with poor reporting, but firms without a substantial increase in reporting incentives around IAS adoption, and hence one would not expect to observe positive market effects. For this reason, we control for the level of reporting incentives in the model. Conversely, the 'label' group can comprise firms with a substantial reduction in reporting incentives around IAS adoption, thereby leading to negative market outcomes. 
heterogeneity in the change in reporting incentives at the time of IAS adoption. Illustrating that the three partitions produce similar results around mandatory IFRS eases this concern and makes it unlikely that heterogeneity in the IAS coding or in the standards is the primary driver of our results because at the time of the mandate heterogeneity in the standards should be minimal. ${ }^{3}$ Instead, it points to reporting incentives as the key source of the heterogeneity in outcomes. We also show that serious and label adoptions occur in all time periods and many countries, and that our main results hold in the early and late part of the sample period.

The paper's two main contributions to the literature are as follows. First, our study is among the first to highlight and test firm-level heterogeneity in the capital-market effects around voluntary and mandatory IAS/IFRS adoptions. Existing studies tend to focus on the average effect of these adoptions with respect to some outcome variable or examine cross-sectional differences at the country level (e.g., Daske et al., [2008], Armstrong et al., [2010], Landsman, Maydew, and Thornock [2012]). ${ }^{4}$ Our study shows that firm-level heterogeneity in reporting incentives plays a significant role for the capital-market effects around IAS/IFRS adoptions. In doing so, we contribute to the literature on the importance of firms' reporting incentives (e.g., Ball, Robin, and Wu [2003], Leuz, Nanda, and Wysocki [2003], Burgstahler, Hail, and Leuz [2006]). Much of this literature has focused on differences in countries' institutions as a driver of reporting incentives. We extend this literature by applying the notion of reporting incentives to within-country tests based on firm-level changes, rather than broad and relatively stable crosscountry differences (in levels). Second, our evidence demonstrates that concerns about selection

3 We further show that the results hold for alternative IAS coding schemes, including a very strict scheme that requires an explicit auditor's attestation of IAS/IFRS reporting, as well as for voluntary U.S. GAAP adoptions.

4 There exist a few studies that provide cross-sectional analyses at the firm level around IAS/IFRS adoptions (e.g., Christensen, Lee, and Walker [2007], Karamanou and Nishiotis [2009], Byard, Li, and Yu [2011]). However, they either have much narrower samples or do not focus on the heterogeneity in the effects and the underlying reasons for it. 
effects around IAS/IFRS adoptions are to be taken seriously, particularly for voluntary adoptions, and that one has to exercise caution in attributing observed capital-market effects solely to the switch in standards. Instead, the effects could also reflect changes in the economics of the firm that affect managers' reporting incentives. On a more descriptive level, the paper makes a third contribution. It provides comprehensive evidence on voluntary IAS reporting around the globe and highlights that, because of the large number of inconsistencies, commonly used accounting standards classifications in Worldscope and Global Vantage have to be used judiciously.

Section 2 develops our hypotheses. In Section 3, we delineate our research design and describe the data. Section 4 presents the analyses and results. Section 5 concludes. In the Appendix we provide a comparison of commonly used accounting standards classifications and describe voluntary IAS/IFRS adoptions around the world.

\section{Hypothesis Development}

The starting point of our study is the notion that the underlying motivations for why managers change standards, including changes in firms' economics, play a significant role for the economic consequences around IAS/IFRS adoptions. Some firms may adopt IAS merely in name without making material reporting changes. For others, economic changes (e.g., new growth opportunities) may provide management with incentives to enhance a firm's reporting strategy and to strengthen its commitment to transparency. In this case, IAS adoption could be part of a broader set of changes. Similarly, there can be heterogeneous incentives around a mandate to report under IFRS; not all firms are likely to equally embrace such a mandate. As a result of such differences in incentives, and provided that markets are able to differentiate between them, there should be predictable heterogeneity in the economic effects around voluntary and mandatory IAS/IFRS adoptions. 
Important antecedents for this paper are studies highlighting the role of firms' reporting incentives in explaining observed accounting properties and actual practices. ${ }^{5}$ IAS or IFRS, like any other set of accounting standards, afford management with substantial discretion as their application involves judgment and the underlying measurements are often based on private information. The way in which firms use this discretion likely depends on managers' reporting incentives, which are shaped by many factors, including countries' institutional frameworks, various market forces, and firm characteristics. In this paper, we emphasize and test the role of firm-level incentives in the context of IAS/IFRS adoptions.

Our main point is that because firms differ with respect to their reporting incentives as well as changes in them over time, it is difficult to attribute capital-market effects around IAS adoptions to the change in the standards alone. Observed capital-market effects around IAS adoptions likely also reflect changes in firm economics including the circumstances that led to IAS adoption in the first place. This creates a difficult identification and selection issue. To illustrate the point, our main hypothesis is that markets react more favorably to IAS adoptions around which firms make material and credible improvements to their overall reporting and disclosure policies. For instance, in a firm with a positive shock to its growth opportunities, management anticipates larger future financing needs, and hence sees more value in improving transparency. ${ }^{6}$ If management increases its commitment to transparency and among several changes voluntarily adopts IAS, then the switch in standards is associated with the change in commitment, but it is not the sole source of the improvement. It merely serves as a proxy. In contrast, markets should not

5 This literature essentially goes back to Watts and Zimmerman [1986]. Recent examples in the international literature are Ball, Kothari, and Robin [2000], Ball, Robin, and Wu [2003], Leuz [2003], Burgstahler, Hail, and Leuz [2006], and Bradshaw and Miller [2008]. These studies primarily focus on country-level incentives.

6 This argument is similar to the bonding hypothesis. U.S. cross-listings are predicted to be more attractive for firms with large financing needs and growth opportunities and to entail higher costs for firms in which insiders consume substantial private benefits of control (e.g., Doidge, Karolyi, and Stulz [2004]). 
react (or could even react negatively) when firms only change the label of their accounting standards without making fundamental changes to their reporting. This heterogeneity provides the motivation for our stylized distinction between 'serious' and 'label' adopters.

Importantly, we do not claim that 'serious' adopters experience positive effects because they comply strictly with IAS. We classify them as such because our proxies indicate a substantial change in the underlying incentives to improve transparency overall. Similarly, we cannot attribute any negative effects around 'label' adoptions to a lack of compliance with IAS. Instead, the effects could simply reflect reduced incentives for transparent reporting. Put differently, we do not attempt to identify the marginal effect of IAS adoption per se. To the contrary, a key point of our study is to illustrate that the estimated IAS coefficient cannot be attributed to the accounting standards alone, but likely also reflects differences in firms' underlying motivations for IAS adoption. Thus, addressing the self-selection inherent in the voluntary adoption of IAS is not appropriate for our purposes, as we aim to highlight its existence, but doing so would be critical for studies aiming to isolate the effects of IAS reporting. Finding heterogeneity in the capital-market effects around IAS adoption does also not imply that standards do not matter. Standards and, specifically, voluntary IAS adoption can play an important role in firms' commitment strategies (e.g., Leuz and Verrecchia [2000]). But the heterogeneity implies that the change in standards alone is likely not responsible for the observed effects.

In principle, there are several additional explanations for heterogeneous capital-market effects around IAS adoptions, which we attempt to rule out or address in our research design. First, it is possible that the use of IAS harmonizes reporting quality across firms. In this case, the heterogeneity in economic consequences around adoption mainly stems from prior reporting differences, rather than differences in firms' motivations for IAS adoption. We therefore should 
see positive capital-market effects for most IAS adopting firms, considering that IAS are viewed as more demanding and capital-market oriented relative to most local GAAP regimes, and the biggest effects should occur for the firms with the lowest reporting quality prior to the switch (all else equal). Given this alternative explanation, we focus on changes in firms' reporting incentives around IAS adoption and include the pre-IAS level of the reporting proxies in the empirical model to control for prior differences in firms' reporting practices.

Second, IAS adoption itself could be almost costless, in particular in countries with lowquality institutions (Ball [2006]). One concern then is that discretion in reporting standards and lack of enforcement make it difficult and very costly for investors to figure out the extent to which firms implement serious changes around IAS adoption. Thus, it is conceivable that there is little (economically meaningful) heterogeneity in the capital-market effects around IAS adoptions because investors cannot discern between serious and label adoptions.

Third, it is possible that the heterogeneity in outcomes around voluntary IAS adoptions reflects heterogeneity in the standards themselves or in how firms use the standards. For instance, the set of IAS has changed and evolved considerably over the years (e.g., as a result of the IASC's Core Standards Project or the Norwalk Agreement). Similarly, firms could use IAS to a varying degree (e.g., some claim to do IAS within the discretion provided by local GAAP while others provide a full-fledged set of IAS statements including auditor attestation). These differences across time and firms could lead to differential market reactions regardless of the underlying reporting incentives. To rule out this explanation, we provide additional tests limiting the heterogeneity in the standards (see Section 4.2).

Finally, we note that it is difficult to predict market reactions around 'label' adoptions. One prediction is that label adoptions have no or a negligible effect. Alternatively, the market reaction 
could be adverse, as a label adoption makes it apparent to investors that a firm is unwilling to commit to more transparency. Moreover, label adoptions could increase investor uncertainty, for example, because the change in standards makes it harder to forecast future earnings. But if markets unravel label adoptions and react unfavorably to them, it poses the question of why firms choose such adoptions in the first place. Again, it is important to recognize that the capital-market effects around 'label' adoptions are not necessarily attributable to the switch in standards per se. A negative market reaction could simply reflect changes in firm economics including a corresponding decrease in the commitment to transparency, rather than a response to the adoption of IAS. It is also possible that label adoptions are not very costly, yet offer (small) benefits that we do not measure in our analysis. For instance, firms could adopt IAS for contracting reasons. IAS could also be an investor-relations tool to improve communications with foreign investors, which could have an impact on foreign holdings, but less of an effect on liquidity (as one group of investors simply replaces another). ${ }^{7}$ It could also be that managers perceive a general trend to IAS and feel compelled to follow, but adopt IAS in the least costly way because there is no reason to adjust the reporting practices. Given all these possibilities, we do not sign our expectation for the effects of label adoptions relative to local GAAP firms. ${ }^{8}$

\section{Research Design and Data}

Our research design relies on variation in the underlying motives for IAS/IFRS adoption. We therefore focus on voluntary adoptions in our main analyses to increase the power of the tests, and

7 For instance, Tan, Wang, and Welker [2011] show that the IFRS mandate has differential effects on analyst forecasts depending on whether the analysts are local or foreign.

8 Yet another explanation is that managers do not believe that markets unravel label adoptions. Prior capitalmarket studies suggest that managers sometimes engage in accounting choices as if markets reward or fixate on these choices, despite the fact that studies show that markets see through these choices (e.g., Watts and Zimmerman [1986], Kothari [2001]). 
use changes in firms' reporting incentives to illustrate the selection issue. Doing so, we need a variable indicating when a firm has voluntarily adopted IAS, a variable capturing the changes in firms' reporting incentives to differentiate between 'serious' and 'label' adopters, as well as proxies for the economic outcomes and a set of controls. We estimate the following model:

$$
\text { EconCon }=\beta_{0}+\beta_{1} I A S+\beta_{2} \text { Serious Adopters }+\sum \beta_{j} \text { Controls }_{j}+\varepsilon \text {. }
$$

EconCon stands for three proxies of economic consequences (i.e., price impact, bid-ask spreads, and cost of capital). IAS is a binary variable coded as ' 1 ' for years in which a firm follows IAS. Serious Adopters denotes a binary classification that identifies firms with above-median changes in our reporting proxies around the adoption of IAS. With this model, we can compare the label adopters to the local GAAP firms $\left(\beta_{1}\right)$, the serious adopters to the label adopters $\left(\beta_{2}\right)$, and the serious adopters to the base group $\left(\beta_{1}+\beta_{2}\right)$. Controls $s_{j}$ denotes a vector of control variables including fixed-effects. The next sections describe each of the model's components.

\subsection{IAS REPORTING AND SERIOUS VERSUS LABEL CLASSIFICATION}

The coding of the IAS variables in Eq. (1) involves three steps. First, we construct a firm-year panel dataset with a binary IAS reporting variable. We deliberately use a broad classification when coding the binary IAS variable. Given our research question, we intend to capture a wide variety of adoption strategies, including firms with dual reporting, those that provide a reconciliation of local GAAP numbers to IAS, and those that merely create the appearance of IAS reporting. That is, our classification relies primarily on what firms claim they do. Second, we determine the actual switch year, i.e., the point in time when IAS reporting started. We provide details on these two steps in the Appendix.

As a third step, we construct three proxies measuring changes in reporting incentives around the switch to IAS. We use these proxies to partition the IAS firms into serious and label adopters. 
The underlying idea is that reporting incentives play a significant role for firms' reporting strategies as well as the choice to voluntarily adopt IAS. Based on this logic, we attempt to identify firms that experience substantial increases in their reporting incentives around IAS adoption. These firms are likely to make major improvements to their reporting strategy. In contrast, there could be firms that adopt IAS without material changes or even decreases in reporting incentives. For example, these firms could adopt IAS because managers perceive a general trend to IAS/IFRS and feel pressured to follow, but then are less likely to materially adjust their reporting. Similarly, they could adopt IAS for contracting reasons and hence not be concerned with transparency to equity investors.

Since reporting incentives are unobservable, we create three distinct proxies for the underlying construct: two focus on the determinants of firms' incentives (and hence are inputbased); one relies on firms' actual reporting behavior as a result of firms' incentives (and hence is output-based). Our first partitioning variable reflects observable firm characteristics. Economic theory suggests that larger, more profitable firms with greater financing needs and growth opportunities, more international operations, and dispersed ownership have stronger incentives for transparent reporting to outside investors. ${ }^{9}$ We measure the Reporting Incentives variable as the first and primary factor (out of three that are retained) when applying factor analysis to the following six firm attributes: firm size (natural log of the US\$ market value), financial leverage (total liabilities over total assets), profitability (return on assets), growth opportunities (book-tomarket ratio), ownership concentration (percentage of closely-held shares), and internationalization (foreign sales over total sales). The factor exhibits all the expected loadings

9 These determinants follow from the disclosure literature (see Leuz and Wysocki [2008] for a survey) and the cross-listing literature (e.g., Lang, Lins, and Miller [2003], Doidge, Karolyi, and Stulz [2004]). 
(i.e., increasing in size, leverage, profitability, growth, and foreign sales; decreasing in ownership concentration). ${ }^{10}$

Our second partitioning variable relies on a simple accrual-based characterization of actual reporting. Sloan [1996] or Bradshaw, Richardson, and Sloan [2001] show that the decomposition of earnings into accruals and operating cash flow as well as extreme accruals contain important information. Furthermore, the ratio of accruals to cash flows has been shown to produce plausible earnings management rankings for firms around the world (Leuz, Nanda, and Wysocki [2003], Wysocki [2004]). ${ }^{11}$ Following Leuz, Nanda, and Wysocki [2003], we compute the Reporting Behavior variable as the ratio of the absolute value of accruals to the absolute value of cash flows (multiplied by -1 so that higher values indicate more transparent reporting). Scaling by the operating cash flow serves as a performance adjustment (Kothari, Leone, and Wasley [2005]). We estimate accruals as the difference between net income before extraordinary items and the cash flow from operations or, if unavailable, compute them following the balance-sheet approach in Dechow, Sloan, and Sweeney [1995]. ${ }^{12}$

10 To maximize sample size we replace missing values for ownership concentration and foreign sales with zero. Unreported sensitivity analyses show that our results do not hinge on the composition of the factor score. When we re-run our analyses eliminating, one-by-one, each firm attribute (or replacing market value with total assets and dropping the book-to-market ratio), the results are not materially affected.

11 We acknowledge that it is difficult to consistently assess the actual reporting behavior across many firms and countries. To mitigate these concerns, we (i) use the reporting variables only to partition the IAS firms and not directly as test variables, (ii) base all our cross-sectional analyses on changes in the reporting incentives proxies, (iii) do not analyze changes in the accruals proxy per se but focus on the capital-market consequences of IAS adoption, and (iv) always include the (pre-IAS) level of our partitioning variable as a control.

12 We recognize that a change in accounting standards could have mechanical effects on the magnitude of accruals. However, as IAS tend to be more accruals-based than local standards around the world (e.g., Hung [2001], Ding et al. [2006]), this effect likely works against our expectations. In addition, we control for the variability in firms' operations as suggested by Hribar and Nichols [2007]. That is, we first regress the ratio of absolute accruals to cash flows on the standard deviation of cash flows, and then use the residuals as our Reporting Behavior variable. This procedure accounts for the variability in operations that potentially biases unsigned accruals measures. The results (not tabulated) remain largely unchanged using this alternative metric. 
The idea behind the third partitioning variable is to capture external changes affecting firms' reporting incentives, such as the scrutiny by analysts and financial markets. Lang and Lundholm [1996] show that analyst coverage is related to more transparent reporting. Evidence in Lang, Lins, and Miller [2004], and Yu [2008] suggests a monitoring role of financial analysts, for instance, in curbing earnings management. We compute the Reporting Environment variable as the natural $\log$ of the number of analysts following the firm (plus one). For firms without coverage in $\mathrm{I} / \mathrm{B} / \mathrm{E} / \mathrm{S}$ we set analyst following to zero. A nice feature of this variable is that it does not rely on accounting information, and is free of mechanical accounting effects that likely occur around the switch to a new set of accounting standards. ${ }^{13}$

Next, to reduce measurement errors and allow for the possibility that incentives change slowly over time, we compute the rolling average (over the years $t, t-1, t-2$, relative to the year $t$ of IAS adoption) for each reporting variable. We then use this rolling average in two ways: first, we include it as a separate control in Eq. (1) for differences in the level of firms' reporting incentives. Higher values indicate stronger incentives for transparent reporting. Second, we compute changes in the reporting variables around IAS adoption by subtracting the rolling average in year $t-1$ (computed over the years $t-3$ to $t-1$ ) from the rolling average in year $t+3$ (computed over the years $t+1$ to $t+3)$. We center the computation on year $t=0$ to obtain non-overlapping observations from the pre and post period and to exclude potentially contaminating effects from the adoption year itself. We then use the distribution of the changes around IAS adoption (with each firm

\footnotetext{
13 We find very similar results using analyst forecast dispersion as a proxy for firms' Reporting Environment (not
} tabulated). 
represented once) to classify IAS firms with above median changes as Serious Adopters (coded as ' 1 ') and with below median changes as label adopters (see also Panel A in Table 4). ${ }^{14}$

We assess the construct validity of the three reporting variables by computing the Spearman correlations between the proxies (ranging from $\rho=0.18$ between Reporting Environment and Reporting Behavior to $\rho=0.54$ between Reporting Environment and Reporting Incentives), and by correlating them with related reporting variables, for which we have only limited samples at hand. For instance, we find significantly positive correlations for the Reporting Incentives and the Reporting Environment variables with (i) a disclosure quality index created by business professionals in Austria, Germany, and Switzerland (Daske and Gebhardt [2006]), (ii) having a Big Five auditor, and (iii) the extent of disclosure (measured by the number of pages in the annual report, after adjusting for country effects, firm size and performance). ${ }^{15}$

\subsection{DEPENDENT VARIABLES}

In studying the economic consequences around IAS adoptions, we use proxies for market liquidity, information asymmetry, and the cost of capital, which - among other things - should reflect the quality of financial disclosure and reporting (e.g., Verrecchia [2001]; Lambert, Leuz and Verrecchia [2007]). This approach sidesteps the difficulties of explicitly measuring changes in reporting quality around IAS adoption.

14 In untabulated sensitivity analyses, we also compute the cut-off value based on the entire distribution of changes in the respective reporting variable around any given year (thus including non-IAS firms and years other than the IAS adoption year). Alternatively, we rank the changes in the reporting variables around IAS adoption into deciles, and then use the ranks to estimate the differential economic consequences of serious and label adopters. In each case, the results look similar to those in the main analysis and none of the inferences change.

15 Ultimately, partitions based on the three proxies are unlikely to produce consistent and sensible results if they fail to capture the underlying construct. In this sense, the cross-sectional analyses can also be seen as a validation exercise of the three partitioning variables. 
The first dependent variable is a measure of illiquidity suggested by Amihud [2002] and inspired by Kyle's [1985] lambda. We measure Price Impact, i.e., the ability of an investor to trade in a stock without moving its price, as the yearly median of the Amihud [2002] illiquidity measure (computed daily and equal to the absolute stock return divided by the US\$ trading volume). Higher values indicate more illiquid stocks. To avoid the misclassification of days with no or low trading activity (i.e., days potentially yielding a price impact of zero), we omit zeroreturn days from the computation of the yearly medians.

The second dependent variable is the Bid-Ask Spread, which is a commonly used proxy for information asymmetry (e.g., Welker [1995], Leuz and Verrecchia [2000], Lang, Lins, and Maffett [2012]). We use the yearly median of the daily quoted spreads, which we compute as the difference between the closing bid and ask prices divided by the mid-point.

The third dependent variable is Cost of Capital. We follow Hail and Leuz [2006] and compute the mean implied cost of equity capital using four models suggested by Claus and Thomas [2001], Gebhardt, Lee, and Swaminathan [2001], Easton [2004], and Ohlson and Juettner-Nauroth [2005]. These models are consistent with discounted dividend valuation but rely on different earnings-based representations. We substitute market price and analyst forecasts into each valuation equation and back out the cost of capital as the internal rate of return that equates current stock price and the expected future sequence of residual incomes or abnormal earnings. See the appendix in Hail and Leuz [2006] for details on the cost of capital proxies we apply. ${ }^{16}$

16 We recognize that there is a debate about the empirical validity of implied cost of capital estimates (e.g., Botosan and Plumlee [2005], Easton and Monahan [2005]). One alternative is to use realized returns as a proxy for expected returns. However, this proxy has many drawbacks as well, especially with short time series (Elton [1999]). We therefore go down a different route and use proxies for liquidity and information asymmetry as these constructs also capture differences in reporting quality (Leuz [2003], Lang, Lins, and Maffett [2012]). 
We measure the dependent variables as of month +10 after the fiscal year end for which we code the accounting standards. We choose this month to ensure that firms' annual reports are publicly available and priced at the time of the computations. For variables that are computed over an entire year, we start the computation as of month -2 through month +10 relative to the firm's fiscal year end.

\subsection{CONTROL VARIABLES}

We include industry-, country-, and year-fixed effects in all regression models, and hence control for differences in countries' adoption rates as well as time trends. In unreported analyses, we also check that our results are robust when we include country-year-fixed effects to control for country-wide shifts in the adoption rates over time, e.g., due to the announcement of mandatory IFRS reporting. Thus, the Serious Adopters coefficient reflects within-country differences relative to local GAAP firms and label adopters.

In addition, we introduce the following binary indicators (see also Daske et al. [2008]): U.S. Listing is equal to one if the shares are traded over-the-counter or cross-listed on a U.S. exchange (Hail and Leuz [2009]). We separately code firms that voluntarily report under U.S. GAAP, but without a U.S. cross listing. We set New Markets equal to one if shares are traded on an exchange, which specializes in technology and other high-growth stocks and has listing requirements that mandate or allow IAS reporting. Index Member represents firms whose shares are constituents of national or international stock market indices as defined in Worldscope.

In the liquidity regressions, we control for firm size, share turnover, and return variability (Chordia, Roll, and Subrahmanyam [2000], Leuz and Verrecchia [2000]). Firm size is the Market Value of equity in US\$ million. Share Turnover is the accumulated US\$ trading volume divided by the market value of outstanding equity. Return Variability is computed as annual standard 
deviation of monthly stock returns. We compute share turnover and return variability from month -2 through month +10 relative to a firm's fiscal year end, and lag the market variables by one year to mitigate confounding effects from contemporaneous measurement.

In the cost-of-capital specifications, we follow Hail and Leuz [2009] and control for firm size measured as Total Assets (in US\$ million), Financial Leverage equal to the ratio of total liabilities to total assets, and Return Variability. We also control for Forecast Bias equal to the one-yearahead analyst forecast error scaled by lagged total assets. First, it is possible that the adoption of IAS impairs analysts' ability to forecast earnings, at least during a transitional period. Second, any bias in analyst forecasts could mechanically affect our implied cost of capital estimate if markets back out the bias (e.g., Botosan and Plumlee [2005], Hail and Leuz [2006]). Finally, we control for inflation because analyst forecasts are expressed in nominal terms and local currency. We measure Inflation as the yearly median of one-year-ahead realized monthly changes in the consumer price index in a country. ${ }^{17}$

\subsection{DATA}

We obtain financial data from Worldscope, return, bid-ask spread, and trading volume data from Datastream, and analyst forecasts and share price data for the cost of capital estimation from I/B/E/S. The sample consists of all Worldscope firms from 1990 to 2005 for which we have the necessary data to compute the variables described above. ${ }^{18}$ Table 1 presents the distribution of firms reporting under IAS/IFRS, U.S. GAAP, or local GAAP by country (Panel A) and year (Panel B). The total sample consists of 69,528 firm-year observations across 30 countries, of

\footnotetext{
Using countries' risk-free rates rather than the inflation rate yields very similar results and inferences.

18 Our main sample ends on December 31, 2005, because IFRS became mandatory in many countries thereafter. We further require firms to have total assets of 10 US\$ million, and countries to have at least one voluntary IAS observation. The latter two design choices do not affect the inferences drawn from the analyses.
} 
which 4,155 are coded as IAS. ${ }^{19}$ The number of IAS firms increases considerably over time. By 2004, almost $9 \%$ of the sample firms have adopted IAS. Similarly, the number of U.S. GAAP firms increases, but remains at a relatively small $2 \%$.

Table 2 presents descriptive statistics for the dependent variables (Panel A) and the control variables (Panel B) across the IAS adopters and local GAAP firms. Spread and price impact are right-skewed and could exhibit multiplicative relations with the control variables. Thus, as is common in the literature on micro-structure models, we estimate a log-linear specification and use the natural log of these measures in the analyses.

\section{Results}

\subsection{AVERAGE EFFECTS ACROSS IAS AND LOCAL GAAP FIRMS}

We begin our analysis by examining average differences in market liquidity and cost of capital between firms reporting under IAS and firms reporting under local GAAP. We use crosssectional, time-series panel regressions, which benchmark IAS firms against local GAAP firms and against their own local GAAP history before adoption. Estimating average effects allows a comparison with prior work. We estimate the empirical specification in Eq. (1), but without the Serious Adopters variable. For each dependent variable, we estimate three regressions using either the level of the Reporting Incentives, the Reporting Behavior, or the Reporting Environment variable as a control. If these proxies capture incentives for more transparent reporting, they

19 In several sample countries, IAS reporting was not permissible to satisfy local reporting requirements during the sample period (e.g., U.K. and Canada). Nonetheless, firms in these countries could voluntarily provide a second set of financial statements in accordance with IAS/IFRS while filing primary accounts that comply with local reporting requirements. We check that our results are not affected by the inclusion of these countries. 
should exhibit a negative coefficient in the model. Table 3 presents results from OLS regressions with robust standard errors that are clustered by firm. ${ }^{20}$

Using price impact as dependent variable, the coefficients on $I A S$ are insignificant, suggesting that firms voluntarily reporting under IAS - on average - have similar liquidity as local GAAP firms. The control variables behave as expected. Importantly, all three reporting variables are negatively associated with price impact, consistent with the idea that these proxies capture firms' incentives for transparent reporting. Moreover, cross listing in the U.S., which among other things represents a commitment to transparency, is associated with a strong reduction in price impact (in line with, e.g., Foerster and Karolyi [1999], and Baruch, Karolyi, and Lemmon [2007]). Both the results for the reporting variables and U.S. cross listing make it unlikely that lack of power is responsible for the weak IAS results. There are also liquidity differentials for firms on new markets (consistent with high growth, high risk firms), constituents of major stock indices (consistent with large, well established and less risky firms), and firms with larger market valuations, higher share turnover, and higher return variability. The coefficient on voluntary U.S. GAAP is insignificant. In the model with firm-fixed effects (not tabulated), the $I A S$ coefficient is significantly negative, providing a first indication that heterogeneity across firms matters.

Next, we present the bid-ask spread results. Two models suggest that firms reporting under IAS have significantly larger spreads; the third model suggests the opposite. This may seem surprising, but it should be noted that in Table 3 we include IAS firms for which we are unable to identify the switch year (see Table A4, Panel B, in the Appendix). Thus, the IAS coefficient could

20 We also estimate the average effects model (i) replacing the country- and industry-fixed effects with firm-fixed effects, and (ii) omitting the IAS firms without identifiable switch year. The first test essentially controls for time-invariant and potentially unobserved differences between firms. The second test limits the sample to the same set of IAS firms that we use in the subsequent cross-sectional analyses. The results of both sensitivity tests (not tabulated) are similar to those reported in the tables, unless we discuss differences in the text. 
also reflect cross-sectional differences between IAS and local GAAP firms that are not fully controlled for in our specification. Consistent with this explanation, the $I A S$ coefficient becomes significantly negative in the firm-fixed effects model (not tabulated). ${ }^{21}$ This finding underscores the importance of requiring a switch year in the subsequent analyses. The control variables exhibit associations similar to those in the price impact model.

The final three columns in Table 3 report the cost-of-capital results. Similar to the spread regressions, two of the $I A S$ coefficients are positive and significant, indicating that IAS firms on average have a higher cost of capital than local GAAP firms. ${ }^{22}$ Unlike for spreads, this result continues to hold in the firm-fixed effects specification (not tabulated). The three reporting variables are always significantly negative, consistent with the idea that these variables capture differences in firms' reporting incentives. ${ }^{23}$ Most of the remaining control variables are highly significant and have the expected signs. ${ }^{24}$

In sum, the three reporting variables exhibit significant associations consistent with the idea that these variables capture differences in firms' reporting incentives. The average economic consequences associated with voluntary IAS adoptions are mixed. One explanation for these mixed results could be substantial heterogeneity across firms, in which case examining the average effect can be misleading. We explore this possibility next. Before that, however, we note

21 Similarly, when we omit IAS firms without identifiable switch year, the $I A S$ coefficients across the three bidask spread models are negative (but only significant in Model 2).

22 Daske [2006], examining a broad sample of German firms, also finds that voluntary IAS adopters exhibit higher costs of equity capital than local GAAP firms.

23 This relation is also economically significant. For instance, a one-standard-deviation increase in the reporting variables implies a decrease in the cost of capital of 183 (Reporting Incentives), 33 (Reporting Behavior), and 43 basis points (Reporting Environment), respectively. More realistically, a one-percent change in the reporting incentives variables implies a decrease in the cost of capital between 1 and 9 basis points.

24 The significantly positive coefficients on U.S. Listing and Total Assets in Model 1 are primarily due to the inclusion of contemporaneous market values when computing the Reporting Incentives variable (see also Hail and Leuz [2009]). When we replace market values with total assets in this computation, we find a significantly negative coefficient for U.S. cross-listings. 
that our findings in Table 3 are important because they are inconsistent with the notion that voluntary IAS adoption itself constitutes a commitment to increased disclosure. Such a commitment effect for the average or most firms would be surprising considering that firms have substantial flexibility in how they adopt IAS, and in light of descriptive evidence that there are major differences in the quality of IAS financial statements (e.g., Cairns [1999], [2001], Barth, Landsman, and Lang [2008]).

\subsection{HETEROGENEITY IN EFFECTS ACROSS SERIOUS AND LABEL ADOPTERS}

We begin the analyses in this section with descriptive statistics for the three reporting variables used to split the voluntary IAS firms into serious and label adopters, and report them in Table 4. In Panel A, we tabulate the level of the reporting variables in the year immediately before the switch to IAS and the changes around IAS adoption that serve to create the binary Serious Adopters indicators. The panel provides three insights. First, the pre-adoption level is substantially higher for label adopters than for serious adopters. This indicates that label adopters have less room for improvement and are not necessarily firms with poor reporting practices to begin with. Second, for serious adopters, the mean (median) change in all three reporting variables is positive, suggesting an increase in their incentives for transparency. Yet, the average change for label adopters is negative. Third, the average changes are quite large suggesting a substantial shift in reporting incentives around IAS adoption. For instance, the mean change in Reporting Incentives equals -0.264 for label adopters and +0.359 for serious adopters, relative to the pre-IAS level of 0.227 . Table 4 also reports the distribution of serious and label adopters by

country (Panel B) and year (Panel C). The two types of firms occur in almost any country and no clustering is apparent. The number of serious adopters exceeds the number of label adopters in the early years, but the pattern reverses in the later years (except for 2004). 
Next, in Table 5, we provide median values and the number of observations for the dependent variables across label and serious adopters, and local GAAP firms. We only include IAS firms with identifiable switch years (to distinguish between serious and label adopters) and 'pure' local GAAP firms (to control for time-period effects). As Panels A and B show, serious adopters have higher stock market liquidity than label adopters, which in turn have higher liquidity than local GAAP firms. For instance, in the Reporting Incentives partition, the price impact for serious adopters is 0.046 compared to $0.111(0.185)$ for label adopters (local GAAP firms). Except in one case, the differences are all statistically significant. In Panel C, we compare the cost of capital across groups. In the Reporting Incentives partition, the serious adopters have lower costs of capital than local GAAP firms; label adopters have the highest costs of capital. The results in the other two partitions are inconclusive (or opposite).

We then present OLS regression estimates of Eq. (1) in Table $6 .{ }^{25}$ For price impact, we find that the coefficients on the Serious Adopters indicator are always negative and significant regardless of the partitioning variable we use. That is, serious adopters are more liquid than label adopters and, as indicated by the significant F-test, more liquid than local GAAP firms. This finding suggests substantial and predictable heterogeneity in the price impact effects, and is consistent with the notion that serious adopters increase their commitment to transparency around IAS adoption. The IAS coefficient is significantly positive in the Reporting Incentives and Reporting Environment partitions, indicating that label adopters exhibit lower market liquidity than local GAAP firms. The control variables behave similar as in Table 3. Notably, the three

25 Compared to Table 3 the number of IAS firms is substantially lower (i) because we omit firms without switch year, and (ii) due to the required data to compute changes in the reporting variables (see also Table 4, Panel A). 
reporting variables (in levels) are still negatively associated with price impact. ${ }^{26}$ The fact that we find higher liquidity for serious adopters after controlling for the pre-IAS level of the respective partitioning variable suggests that our results are not driven by prior differences in reporting incentives. It is also inconsistent with the notion that voluntary adoptions lead to a convergence of reporting practices.

The bid-ask spread results closely resemble those for price impact. The Serious Adopters coefficient is always significantly negative and so is the joint effect with the $I A S$ variable. Thus, serious adopters have smaller bid-ask spreads compared to label adopters and local GAAP firms. For the label adopters, the effect is significantly positive in two of the three regressions. To gauge the economic magnitude, we compare the post-adoption means with the pre-adoption mean spread under local GAAP (i.e., 0.033 in Table 2, Panel A). The coefficients in Table 6 indicate an average decrease in spreads for serious adopters between 6.9 percent (Reporting Environment) and 11.4 percent (Reporting Incentives). Label adopters see a modest increase of 6.4 percent (Reporting Incentives) or smaller. The spread differences between serious and label adopters range from 17.8 percent (Reporting Incentives) to 7.6 percent (Reporting Behavior). ${ }^{27}$ These effects are economically significant, as we would expect if these firms experience large changes in their reporting incentives and, in turn, make changes to their commitment to transparency.

For the cost of capital, we find that serious adopters exhibit a significantly lower cost of capital than label adopters in two of the three models. However, compared to local GAAP firms, the net effect is significantly negative only in the Reporting Incentives partition. In the remaining

26 We compute the reporting variables for the respective year, except for IAS firms, for which we use the pre-IAS mean. Using the pre-IAS level in the panel regression prevents these variables from picking up the changes in reporting incentives around IAS adoption, which we use to construct the serious versus label partitions.

27 The economic magnitudes are in a similar range for the other two dependent variables (i.e., slightly lower for the cost of capital and larger for price impact). 
cases, the combined coefficient is not distinguishable from zero. Thus, there is at best weak evidence suggesting a decline in the cost of capital for serious adopters. Furthermore, the IAS main effect is significantly positive throughout, suggesting that label adopters have a higher cost of capital than local GAAP firms.

As discussed in Section 2, there are several explanations for the positive $I A S$ coefficients in the liquidity and cost of capital regressions. First, it is important to recall that our analysis so far cautions us against interpreting the positive coefficients as attributable to label adoption per se. They likely reflect the negative changes in firms' reporting incentives around IAS adoption, and hence a deterioration of transparency (see Panel A of Table 4). In that sense, seeing adverse economic consequences around IAS adoption is not surprising. That said, there are other possible explanations. For instance, label adoptions might not be that costly to begin with and firms could obtain other (small) benefits (that we do not analyze), which in turn make label adoptions worthwhile. ${ }^{28}$ Alternatively, managers could perceive a general trend to IAS/IFRS and feel pressured to follow, even though they do not want to adjust their reporting practices by much. ${ }^{29}$ We further note that the positive $I A S$ coefficients are less robust than the negative (incremental) effect of serious adoption (see also Section 4.4).

In sum, the cross-sectional analyses confirm our main hypothesis that there is substantial heterogeneity in economic outcomes around IAS adoptions, and that these differences predictably

28 It could be that IAS adoption is a public relations tool for these firms (e.g., in communications with foreigners) and that it has an impact on foreign holdings, but less so on liquidity as one group of investors simply replaces another (e.g., Covrig, DeFond, and Hung [2007]). See also Tan, Wang, and Welker [2011] for related results.

29 Consistent with such a 'bandwagon' effect, label adoptions become relatively more frequent as the trend towards IAS accelerates (see Table 4, Panel C). We also note that there are a large number of serious adopters in 2004. These firms are likely stronger firms that voluntarily adopt ahead of the IFRS mandate to signal their type (see also Daske et al. [2008]). In addition, when we re-estimate our main regressions separately for the subperiods pre and post the completion of the IASC's Core Standards Project in 1997 (not tabulated), we find that the main effect of the IAS indicator variable is generally more positive in the post-1997 period. This is what one would expect if these firms are compelled by the overall trend towards IAS/IFRS. 
line up with the degree to which firms exhibit substantial changes in their reporting incentives. In addition, the findings suggest that (at least some) investors can successfully distinguish between different adoption types and do not reward all firms irrespective how they adopt IAS.

\subsection{HETEROGENEITY IN THE STANDARDS AND MANDATORY IFRS ADOPTION}

In this section, we explore the alternative explanation that heterogeneous effects around voluntary IAS adoptions reflect heterogeneity in the standards that are being adopted. The set of IAS has changed considerably over the years. Similarly, firms do not always fully adopt IAS. Such heterogeneity across time and firms could lead to differential effects across voluntary IAS adoptions, and hence could be a potential explanation for our findings.

We conduct three sets of tests to gauge the importance of this explanation: first, we reestimate our analyses using a very narrow definition of what constitutes voluntary IAS thereby reducing the heterogeneity in the standards that voluntary IAS adopters follow. Second, we apply the serious versus label distinction to firms around the mandatory switch to IFRS. In principle, our reporting incentives argument should also apply to mandatory IFRS adopters, in particular considering that the mandate forces firms to adopt IFRS, and hence there are likely some firms that would have preferred to continue reporting under local GAAP. At the same time, heterogeneity in the standards is less of an issue for mandatory IFRS adoption. Thus, if our results for voluntary adoptions were driven primarily by heterogeneity in the standards, we should not obtain similar or at least considerably weaker results around mandatory adoptions. Third, we study voluntary U.S. GAAP adoptions, for which there has been a complete set of accounting standards for the entire sample period. We present the results from the first two tests in this section. The voluntary U.S. GAAP results follow in Section 4.4. 
Table 7, Panel A, reports liquidity and cost-of-capital results across serious and label adopters using a very strict (and narrow) definition of what constitutes IAS reporting. That is, starting with the augmented Worldscope accounting standards classification, we impose two additional criteria: first, we limit the sample period to the years 1998 to 2005. In 1998, the IASC finished a major revision of its core standards and from this point onwards IAS were considered a complete set of standards. The revised standards also eliminated many optional accounting treatments. Second, we require an explicit auditor attestation of compliance with IAS or IFRS. To do so, we manually check whether the auditor's report contains a statement like "in our opinion, the consolidated financial statements ... are in accordance with the IAS as issued by the IASB. ${ }^{״ 30}$

As shown in the table, using a stricter IAS definition nearly cuts the sample of IAS firms in half, and we lose several countries for which there are no longer any IAS adopters. Nonetheless, the results remain very similar to those before. Even for this narrow sample, there is no evidence that IAS adoption on average improves liquidity or lowers the cost of capital. For both liquidity variables, the Serious Adopters coefficient (net effect) is negative and generally significant, indicating that serious adopters have lower price impact and bid-ask spreads than label adopters (local GAAP firms). The cost-of-capital results are similar to Table 6, except that serious adopters are not different from local GAAP firms in a statistical sense.

Next, we apply our partitioning technique to mandatory IFRS adoption. We limit the sample to the subset of countries from Table 1 that switched to IFRS reporting for consolidated financial statements by the end of 2005, and only cover the years 2002 to 2005 . We define a binary IFRS indicator for firms that are required to adopt IFRS for the first time, and use it in place of the IAS

30 To avoid a reduction in sample size due to gaps in our panel of annual reports, we require such a statement within the first three years after IAS adoption. However, the results are qualitatively the same if we limit the analyses to IAS firms with an auditor's attestation in the actual year of the switch. 
variable. Consequently, we identify the market effects relative to the firms' own pre-adoption years and the firms in the same countries that have not yet or did not adopt IFRS (i.e., we eliminate voluntary IAS firms from the analyses). We split the mandatory IFRS adopters into serious and label firms using the same partitioning technique as before. For each reporting variable we compute the change around the mandated switch (thereby utilizing data up to 2008), and assign the Serious Adopters indicator to the firms with above-median changes. The rest of the model specification is the same as in Eq. (1).

Panel B of Table 7 reports the results for liquidity and cost of capital around mandatory IFRS adoption. Throughout, the Serious Adopters coefficient is negative and, with one exception, significant. Hence, firms with relatively large increases in reporting incentives exhibit higher liquidity and lower cost of capital than firms that adopt IFRS only in name. In five out of the nine specifications, market liquidity (cost of capital) is also significantly higher (lower) for serious adopters than for local GAAP firms. Moreover, price impact and bid-ask spreads are higher for label adopters than for local GAAP firms. Such a positive coefficient on IFRS is not surprising if we correctly identify firms that were forced to adopt IFRS, but would have preferred local GAAP (see also Christensen, Lee, and Walker [2007]). This could also explain why the adverse effects for label adoptions appear to be larger around the mandate than around voluntary adoption.

Overall, the evidence around mandatory adoptions is similar to the evidence around voluntary adoptions. This similarity makes it unlikely that heterogeneity in the standards across firms or time is the primary driver of our results. More importantly, the evidence in this section suggests that reporting incentives also matter for market outcomes around changes in mandatory reporting. 


\subsection{SENSITIVITY ANALYSES}

In this section, we test the sensitivity of our results to various research design choices and report results in Table 8. For brevity, we tabulate only the coefficients and t-statistics of the two IAS variables but, unless stated otherwise, estimate the regressions using the same models as in Table 6. First, in Panel A, we extend the analysis to three additional economic outcomes, namely Total Trading Costs (equal to the roundtrip transaction costs drawn from Lesmond, Ogden, and Trzcinka [1999]), Zero Returns (equal to the yearly proportion of trading days without stock price movements), and firm value defined as Tobin's $q$. For a description of the variables and regression models see the notes to Table 8 . The results using total trading costs are very similar to the liquidity results presented above. Serious adopters have lower trading costs than label adopters. The results are weaker using zero return days, but point in the same direction. In both cases, the net effect for serious adopters is significantly negative. The effect for label adopters is negative and significant in five out of six cases, indicating that the 'adverse' effects of label adoptions shown in Table 6 depend on the outcome variable and are not very robust. The Tobin's q results are consistent with the cost-of-capital effects. In particular, serious adopters have higher firm values than label adopters and, in one case, than local GAAP firms. ${ }^{31}$

Second, in Panel B, we evaluate whether the results are confined to IAS/IFRS. ${ }^{32}$ We extend the analysis by including voluntary U.S. GAAP adoptions by non-U.S. firms (that are not cross-

31 Based on the mean pre-adoption Tobin's q under local GAAP, serious adopters increase their q, on average, between 2.3 percent (Reporting Environment) and 13.7 percent (Reporting Incentives). Label adopters see a decrease between 3.9 percent (Reporting Behavior) and 23.4 percent (Reporting Incentives). These effects are economically significant and quite large (i.e., larger than the average effects of mandatory IFRS adoption in Daske et al. [2008], but smaller than the effects of U.S. cross-listing in Doidge, Karolyi, and Stulz [2004]). But again, these effects should not be attributed to IAS/IFRS alone as they likely also reflect more fundamental changes (which happen to be correlated with IAS adoption).

32 From here on, we report only the results for price impact as the dependent variable in the table, but the inferences are similar using bid-ask spreads and cost of capital. 
listed in the U.S.). Combining IAS and U.S. GAAP or, alternatively, considering only voluntary U.S. GAAP adoptions yields essentially the same insights as before. Market liquidity is highest for serious adopters, while the differences between local GAAP firms and label adopters are usually not significant. These results highlight that our findings for the reporting partitions are not specific to voluntary IAS adoptions. Next, in tests not tabulated, we re-run our analyses using (i) the original Worldscope classification, (ii) the original Global Vantage classification, and (iii) the sub-sample of firms with manually coded accounting standards. We find that serious adopters have significantly higher levels of liquidity compared to label adopters and local GAAP firms, regardless of the accounting standards classification. This result may seem surprising in light of the many misclassifications across data sources documented in the Appendix. However, because our partitioning is independent of the accounting standards classification, it is also possible that many misclassifications end up in the label adopter category, for which we do not predict significant market reactions.

Third, in Panel C, we gauge the effects of sample composition. We re-estimate the models excluding observations from the two countries with the largest contribution to the overall sample (i.e., the U.K. and Canada). Both countries did not allow IAS reporting for statutory purposes, and hence they have a small number of voluntary IAS adopters. Next, we limit the sample to only firms that actually switch to IAS reporting (reducing the sample to about 4,000 firm-years). The results indicate that our analyses remain largely unaffected by the differing sample definitions. ${ }^{33}$

One concern about the research design is that several of our control variables as well as the inputs for the Reporting Incentives and Reporting Behavior variables use accounting numbers and

33 In further tests (not tabulated), we confirm that our results hold when we eliminate all sample restrictions (increasing the sample to 50 countries and a maximum of 135,538 firm-years), and when we use a random benchmark sample consisting of up to 150 non-IAS adopting firms per country and year. 
that these numbers might change mechanically as a result of the switch to a different set of accounting standards. With regard to this concern, we first note that the models that combine liquidity proxies with the partition based on changes in analyst following do not rely on any accounting data. Table 6 shows that the results for these specifications are similar to the other models. Thus, we do not think that mechanical effects from the change in accounting standards induce our findings. Moreover, in Panel D of Table 8, when we re-estimate the cross-sectional analyses using firm-fixed effects and eliminate time-invariant unobserved firm attributes as potentially confounding factors, the results continue to hold, and the inferences are essentially the same as in our main analysis.

Finally, in untabulated analyses, we explore the interplay between firm-level incentives and country-level institutional factors, which could act as substitutes or complements. For instance, in countries with strong capital-market incentives, one would expect firms to already report in a transparent fashion (under local GAAP) and hence when they switch to IAS, they do not need to improve their reporting. In contrast, firms in countries with weak institutions could seek to commit to more transparency (e.g., because they face new growth opportunities), and hence they adopt a series of measures to improve transparency, one of which is IAS. As shown in Panel B of Table 4, we do not observe any clustering of serious and label adoptions in certain countries. To assess this relation more formally, we run three additional tests. First, we construct two-by-two contingency tables for serious and label adopters with two commonly used country-level institutional factors, each split by the median (i.e., the Djankov, La Porta, and Lopez-de-Silanes [2008] anti-self dealing index, and the La Porta et al. [1997] rule of law index). We generally find no statistical relation. Second, we compute the Pearson correlation coefficients between the proportion of serious adopters per country and the two country-level factors. The correlations are 
not significant. Third, we partition the sample countries into two groups and re-run our main regression analyses. We find that the heterogeneity in the capital-market effects around IAS adoption is present within countries with weak and strong institutions and not limited to a particular group of countries. These results are consistent with firm-level incentives having separate effects around IAS adoption that go beyond the effects of country-level institutions.

\section{Conclusion}

This paper examines the economic consequences associated with voluntary and mandatory IAS/IFRS adoptions around the world. We focus on firm-level heterogeneity in the consequences, recognizing that firms can differ in their motivations and ways to adopt IAS/IFRS. Some firms may adopt new standards merely in name without making material changes to their reporting policies, while others adopt them as part of a broader strategy to strengthen their commitment to transparency. The possibility of such differences implies significant heterogeneity in the economic consequences around IAS/IFRS adoptions due to selection effects.

To show the existence of such effects, we create three binary partitions that attempt to capture major changes in firms' reporting incentives around voluntary IAS adoptions (based on various firm attributes, firms' actual reporting behavior, and the external pressure from the reporting environment). We then examine the economic consequences around IAS adoptions for 'label' and 'serious' firms in a large global panel from 1990 to 2005.

We find little evidence that voluntary IAS adoptions are, on average, associated with an increase in market liquidity or a decline in the cost of capital. If anything, the effects go in the opposite direction. However, using our three partitions, we document substantial differences in the capital market effects around IAS adoptions and find that concurrent changes in firms' reporting incentives play a significant role in explaining them. Specifically, serious adopters 
exhibit economically and statistically lower price impact of trades, bid-ask spreads, and costs of capital relative to label adopters and local GAAP firms. Given that we use changes in the incentives variables to partition IAS adoptions and include the corresponding pre-IAS level as a control in the model, our results are unlikely to reflect prior differences in reporting incentives, reporting quality, or the reporting environment.

Our evidence is inconsistent with the notion that IAS reporting per se constitutes a commitment to increased transparency. Consequently, one has to exercise caution in attributing capital market effects around voluntary IAS adoptions solely to the change in accounting standards. The observed effects are more likely to reflect changes in firms' reporting incentives, including those that give rise to the decision to adopt IAS in the first place. One implication is that one could find, on average, positive, negative, or no capital-market effects around IAS adoptions depending on the composition of the sample, unless such differences are accounted for. As such, our results help explain the mixed findings in prior literature.

Our study also contributes to the literature on the role of incentives for reporting outcomes and their capital-market effects. It highlights the role of firm-level incentives (in addition to or separate from country-level incentives) around voluntary IAS adoptions. The findings extend to voluntary U.S. GAAP adoptions and, more importantly, to mandatory IFRS adoptions. Furthermore, our study shows that markets can differentiate between serious and label adoptions. This is important as there is considerable concern that the global movement towards a single set of accounting standards masks the heterogeneity in actual reporting practices and makes it harder for investors to evaluate firms' reporting quality. Our results do not support this concern.

Finally, we caution the reader that our results should not be interpreted as indicating that 'serious' adopters experience the documented effects because they strictly comply with 
IAS/IFRS. Our partitions merely indicate that these firms experience substantial changes in their reporting incentives around IAS/IFRS adoption, which likely influences their reporting behavior more generally. For such firms, the market reaction likely reflects changes in the entire reporting or commitment strategy, not just the switch to IAS/IFRS. Thus, a key message of our paper is that in order to isolate the marginal effects of IAS/IFRS reporting, one has to push harder on the identification of such effects and, in particular, needs to separate them from reporting incentive effects. For this very reason, our results should not be read as suggesting that standards do not matter. While we show that reporting incentives play an important role for the sign and magnitude of the market reactions around IAS/IFRS adoptions, our tests are not designed to analyze the relative contribution of standards and incentives. We leave this issue to future research. 


\section{APPENDIX \\ Classification of Voluntary IAS Adoptions around the World}

This appendix describes our coding of firm-year observations from firms following IAS/IFRS, U.S. GAAP, or local GAAP, and compares accounting standards classifications across different data sources. ${ }^{34}$ It also documents firms' reporting patterns across countries and over time, and how we identify the year of voluntary IAS adoption.

We use three main data sources to construct our panel of firms' accounting standards: (i) Thomson Financial Worldscope (WS), (ii) Compustat Global Vantage (GV), and (iii) an extensive manual review of annual reports collected through Thomson Research. WS serves as starting point because its coverage is by far the most comprehensive. In addition, it is directly linked to Datastream, thereby reducing the potential for mismatches from combining accounting data with price data. Using the information on accounting standards followed (field 07536), we classify firm-year observations into the three categories IAS, U.S. GAAP, and local GAAP according to Panel A of Table A1. To assess the quality of commercially available databases, we also classify the same set of observations applying the GV coding scheme in Panel B of Table A1 that is based on the accounting standards information in field "ASTD". ${ }^{35}$

We next conduct an extensive manual data collection and classification. We start by identifying potential voluntary IAS or U.S. GAAP adopters, i.e., firms with at least one firm-year coded as IAS or U.S. GAAP in either WS or GV before the end of 2005 (35,633 firm-years). We

34 We further illustrate our hand-coding providing examples of each case using excerpts from firms' annual reports in an online appendix (available at http://research.chicagobooth.edu/arc/journal/onlineappendices.aspx). On this site, we also make the database of voluntary IAS reporting available for download.

35 One of the drawbacks of commercial databases is that they attempt to capture many different reporting practices around the world, but often at the expense of consistency through time or across countries. Furthermore, the categories often do not provide clear distinctions between local GAAP and IAS, as is needed for our study. For instance, category 02 "International standards" in WS comprises not only IAS observations, but also firms following other non-local, non-U.S. standards (e.g., H.K. GAAP, U.K. GAAP). This problem is even more pronounced in $\mathrm{GV}$ as it has only three categories dedicated to international standards. 
then gather the time-series of annual reports through Thomson Research, and were able to collect 22,213 documents in electronic image format. Based on a manual review of the accounting principles' footnote and the auditors' report, we create our own accounting standards classification. We deliberately use a broad classification when coding the binary IAS variable. Given our research question, we intend to capture a wide variety of adoption strategies, including dual reporting, reconciliations of local GAAP numbers to IAS, or firms that merely create the appearance of IAS reporting. That is, our classification relies primarily on what firms claim they do. This leads to six reporting categories ranging from the exclusive use of IAS for consolidated financial statements to reporting under local GAAP together with a reconciliation of net income and/or shareholders' equity to IAS (Table A1, Panel C). Importantly, for our manual coding, we require that the annual report contains an explicit reference to IAS/IFRS (U.S. GAAP) for the financial statements in the footnotes. We classify firms as local when they adopt only individual IAS or U.S. GAAP standards (e.g., for leasing or segment reporting). Finally, we complete firms' time-series by filling in cases with missing individual annual reports, utilizing all data sources at hand (i.e., WS, GV, annual reports). This procedure results in a total hand-coded sample of 27,589 firm-year observations.

The main purpose of this massive hand-collection is to assess the suitability of commercially available databases for our research question. To gauge the effect of potential misclassifications, we tabulate firm-years across different classifications and report the number of observations and percentages in Table A2. For ease of comparison, we use the base sample from our main analyses $(\mathrm{n}=69,528)$. In Panel A, we compare the classifications across WS and GV. For our comprehensive WS coding (i.e., when using all categories listed in Table A1), we find that 2.4\% of all firm-years are coded as IAS in WS but as local GAAP in GV (compared to $1.2 \%$ the other way round). Thus, the two data sources provide contradictory information on about every third 
IAS firm-year observations (i.e., [7+844]/2,852 $\approx 30 \%$ when starting with GV; [26+1,658]/3,685 $\approx 46 \%$ when starting with WS). When we limit the WS coding to categories 02 and 23 and the GV coding to "DI" (labeled "Stricter Coding for IAS" in Panel A), the contradiction rates remain substantial (i.e., $[7+921] / 2,728 \approx 34 \%$ for GV; $[1+737] / 2,538 \approx 29 \%$ for WS). Panel B reports results from comparing the hand-coded classification to WS and GV. Neither commercial database clearly dominates, but both exhibit substantial classification differences relative to our manual review of annual reports, as indicated by large numbers of observations off the diagonals. Our hand-coding disagrees in about $25 \%$ of the cases with WS or GV, computed as the fraction of off-diagonal observations relative to the observations for which we have annual report data and WS (GV) information. Panel C reports Pearson correlations between the classifications.

As a further validity check we compare the three coding schemes on a country-by-country basis. In Table A3 we tabulate the numbers and proportions of IAS and U.S. GAAP firms for all countries with a minimum of 20 observations and total assets available in a given year. The table highlights the larger coverage in WS, which identifies more than twice as many IAS firm-years than GV (13,001 versus 6,227). The hand-coded sample consists of 8,399 IAS firm-years. It further reveals that the proportion of IAS firms at the individual country-level varies substantially. For instance, the percentage of IAS adopters in Italy is as high as $78.7 \%$ according to WS but only $0.2 \%$ based on GV. The hand-coding, to which we added observations that are classified as local under both WS and GV, indicates a proportion of $25.1 \%$.

As a result of the above validity checks, we conduct our main analyses using an 'augmented' WS accounting standards classification, for which we use our hand-coded data together with the "Accounting Standard" field in GV to triangulate and correct the initial WS coding. This leads to 2,202 cases for which our hand-coded data overrides conflicting WS information. Unless 
indicated otherwise, the results presented in the study rely on the augmented WS coding to identify the IAS firm-year observations. ${ }^{36}$

The final step involves identifying the switch year. As Table A4 illustrates, voluntary IAS adoption and reporting over time has taken many different forms and patterns. In its simplest form, a firm starts out reporting in accordance to local GAAP and then switches to IAS. In more complicated cases, firms switch back and forth between local GAAP and IAS multiple times, and also might switch to reporting in accordance with U.S. GAAP, for instance, as a result of a U.S. cross-listing. We assign IAS switch years only if we can manually confirm that out of two consecutive firm-years the first is classified as local GAAP and the second as IAS. ${ }^{37}$ Consequently, we identify 845 firms with proper IAS switch years (Panel A), and exclude 570 IAS reporting firms from the serious versus label partitions because we are unable to identify a switch year according to our definition (Panel B). ${ }^{38}$

36 For sensitivity purposes, we also re-run the analyses with the pure Worldscope, Global Vantage, or hand-coded classifications. In addition, we conduct tests using only IAS firms for which we can manually confirm IAS/IFRS reporting via explicit audit firm attestation in the annual report. See Sections 4.3 and 4.4 for details.

37 We manually ensure that the splicing of different data sources does not introduce artificial IAS adoption years. Moreover, we do not consider a switch from U.S. GAAP to IAS as creating a valid switch year.

38 We check that our results are not confounded by the many variations in firms' IAS adoption patterns (not tabulated). Even in the most restrictive case, when we limit the group of IAS adopters to the 696 firms with only one switch from local GAAP to IAS, the inferences of our analyses remain unaffected. 


\section{REFERENCES}

AMIHUD, Y. "Illiquidity and Stock Returns." Journal of Financial Markets 5 (2002): 31-56.

ARMSTRONG, C.; M. BARTH; A. JAGOLINZER; AND E. RIEDL. "Market Reaction to the Adoption of IFRS in Europe.” The Accounting Review 85 (2010): 31-61.

BALL, R. "Infrastructure Requirements for an Economically Efficient System of Public Financial Reporting and Disclosure." Brookings-Wharton Papers on Financial Service (2001): 127-69.

BALL, R. "IFRS: Pros and Cons for Investors." Accounting and Business Research, International Accounting Policy Forum (2006): 5-27.

BALL, R.; S.P. KOTHARI; AND A. ROBIN. "The Effect of International Institutional Factors of Properties of Accounting Earnings." Journal of Accounting and Economics 29 (2000): 1-51.

BALL, R.; A. ROBIN; AND J. WU. "Incentives Versus Standards: Properties of Accounting Income in Four East Asian Countries." Journal of Accounting and Economic 36 (2003): 23570.

BARTH, M. "Global Financial Reporting: Implications for U.S. Academics." The Accounting Review 83 (2008): 1159-79.

BARTH, M.; W. LANDSMAN; AND M. LANG. "International Accounting Standards and Accounting Quality." Journal of Accounting Research 46 (2008): 467-98.

BARUCH S.; G. A. KAROLYI; AND M. LEMMON. "Multi-Market Trading and Liquidity: Theory and Evidence.” The Journal of Finance 62 (2007): 2169-200.

BOTOSAN, C., AND M. PLUMLEE. "Assessing Alternative Proxies for the Expected Risk Premium." The Accounting Review 80 (2005): 21-53.

BRADSHAW, M., AND G. MILLER. "Will Harmonizing Accounting Standards Really Harmonize Accounting? Evidence from Non-U.S. Firms Adopting U.S. GAAP." Journal of Accounting, Auditing and Finance 23 (2008): 233-64.

BRADSHAW, M.; S. RICHARDSON; AND R. SLOAN. "Do Analysts and Auditors Use Information in Accruals?" Journal of Accounting Research 39 (2001): 45-74.

BURGSTAHLER, D.; L. HAIL; AND C. LEUZ. "The Importance of Reporting Incentives: Earnings Management in European Private and Public Firms." The Accounting Review 81 (2006): 983-1017.

BYARD, D.; Y. LI; AND Y. YU. "The Effect of Mandatory IFRS Adoption on Financial Analysts' Information Environment.” Journal of Accounting Research 49 (2011): 69-96.

CAIRNS, D. International Accounting Standards Survey. LLP Professional Publishing, 1999.

CAIRNS, D. International Accounting Standards Survey 2000: An Assessment of the Use of IAS in the Financial Statements of Listed Companies. Henley on Thames, 2001.

CAMPBELL, J. "Understanding Risk and Return." Journal of Political Economy 104 (1996): 298-345.

CHORDIA, T.; R. ROLL; AND A. SUBRAHMANYAM. "Co-Movements in Bid-Ask Spreads and Market Depth.” Financial Analysts Journal 56 (2000): 23-27.

CHRISTENSEN, H.; L. HAIL; AND C. LEUZ. "Mandatory IFRS Reporting and Changes in Enforcement." Working Paper, University of Chicago and University of Pennsylvania, 2012. 
CHRISTENSEN, H.; E. LEE; AND M. WALKER. "Cross-Sectional Variation in the Economic Consequences of International Accounting Harmonization: The Case of Mandatory IFRS Adoption in the UK." International Journal of Accounting 42 (2007): 341-79.

CLAUS, J., AND J. THOMAS. "Equity Premia as Low as Three Percent? Evidence from Analysts' Earnings Forecasts for Domestic and International Stock Markets." The Journal of Finance 56 (2001): 1629-66.

COVRIG, V.; M. DeFOND; AND M. HUNG. "Home Bias, Foreign Mutual Fund Holdings, and the Voluntary Adoption of International Accounting Standards." Journal of Accounting Research 45 (2007): 41-70.

DASKE, H. "Economic Benefits of Adopting IFRS or US-GAAP: Have the Expected Costs of Equity Capital Really Decreased?” Journal of Business Finance and Accounting 33 (2006): 329-73.

DASKE, H., AND G. GEBHARDT. "International Financial Reporting Standards and Experts' Perceptions of Disclosure Quality." Abacus 42 (2006): 461-98.

DASKE, H.; L. HAIL; C. LEUZ; AND R. VERDI. "Mandatory IFRS Reporting Around the World: Early Evidence on the Economic Consequences." Journal of Accounting Research 46 (2008): 1085-142.

DECHOW, P.; W. GE; AND C. SCHRAND. "Understanding Earnings Quality: A Review of the Proxies, their Determinants and their Consequences." Journal of Accounting and Economics 50 (2010): 344-401.

DECHOW, P.; R. SLOAN; AND A. SWEENEY. "Detecting Earnings Management." The Accounting Review 70 (1995): 193-225.

DING Y.; O.-K. HOPE; T. JEANJEAN; AND H. STOLOWY. "Differences between Domestic Accounting Standards and IAS: Measurement, Determinants and Implications." Journal of Accounting and Public Policy 26 (2006): 1-38.

DJANKOV, S.; R. LA PORTA; F. LOPEZ-DE-SILANES; AND A. SHLEIFER. "The Law and Economics of Self-Dealing." Journal of Financial Economics 88 (2008): 430-65.

DOIDGE, C.; G. A. KAROLYI; AND R. STULZ. "Why are Foreign Firms Listed in the U.S. Worth More?" Journal of Financial Economics 71 (2004): 205-38.

EASTON, P. "PE Ratios, PEG Ratios, and Estimating the Implied Expected Rate of Return on Equity Capital." The Accounting Review 79 (2004): 79-95.

EASTON, P., AND S. MONAHAN. "An Evaluation of Accounting-Based Measures of Expected Returns." The Accounting Review 80 (2005): 501-38.

ELTON, E. "Expected Return, Realized Return and Asset Pricing Tests." The Journal of Finance 54 (1999): 1199-220.

FOERSTER, S., AND G. A. KAROLYI. "The Effects of Market Segmentation and Investor Recognition on Asset Prices: Evidence from Foreign Stocks Listing in the United States." The Journal of Finance 54 (1999): 981-1013.

GEBHARDT, W.; C. LEE; AND B. SWAMINATHAN. "Toward an Implied Cost of Capital." Journal of Accounting Research 39 (2001): 135-76. 
HAIL, L., AND C. LEUZ. "International Differences in the Cost of Equity Capital: Do Legal Institutions and Securities Regulation Matter?" Journal of Accounting Research 44 (2006): 485-531.

HAIL, L., AND C. LEUZ. "Cost of Capital Effects and Changes in Growth Expectations Around U.S. Cross-Listings.” Journal of Financial Economics 93 (2009): 428-54.

HAIL, L.; C. LEUZ; AND P. WYSOCKI. "Global Accounting Convergence and the Potential Adoption of IFRS by the U.S. (Part I): Conceptual Underpinnings and Economic Analysis." Accounting Horizons 24 (2010): 355-94.

HRIBAR, P., AND C. NICHOLS. "The Use of Unsigned Earnings Quality Measures in Tests of Earnings Management.” Journal of Accounting Research 45 (2007): 1017-53.

HUNG, M. "Accounting Standards and Value Relevance of Financial Statements: An International Analysis." Journal of Accounting and Economics 30 (2001): 401-20.

KARAMANOU, I., AND G. NISHIOTIS. "Disclosure and the Cost of Capital: Evidence from the Market's Reaction to Firm Voluntary Adoption of IAS." Journal of Business Finance and Accounting 36 (2009): 793-821.

KOTHARI, S.P. "Capital Markets Research in Accounting." Journal of Accounting and Economics 31 (2001): 105-231.

KOTHARI, S.P.; A. LEONE; AND C. WASLEY. "Performance Matched Discretionary Accrual Measures." Journal of Accounting and Economics 39 (2005): 163-97.

KYLE, A. “Continuous Auctions and Insider Trading.” Econometrica 53 (1985): 1315-35.

LAMBERT, R.; C. LEUZ; AND R. VERRECCHIA. “Accounting Information, Disclosure, and the Cost of Capital." Journal of Accounting Research 45 (2007): 385-420.

LANDSMAN, W.; E. MAYDEW; AND J. THORNOCK. "The Information Content of Annual Earnings Announcements and Mandatory Adoption of IFRS." Journal of Accounting and Economics 53 (2012): 34-54.

LANG, M.; K. LINS; AND M. MAFFETT. "Transparency, Liquidity, and Valuation: International Evidence on When Transparency Matters Most." Journal of Accounting Research 50 (2012): 729-74.

LANG, M.; K. LINS; AND D. MILLER. "ADRs, Analysts, and Accuracy: Does Cross Listing in the United States Improve a Firm's Information Environment and Increase Market Value?" Journal of Accounting Research 41 (2003): 317-45.

LANG, M.; K. LINS; AND D. MILLER. "Concentrated Control, Analyst Following, and Valuation: Do Analysts Matter Most When Investors Are Protected Least?" Journal of Accounting Research 42 (2004): 589-623.

LANG, M., AND R. LUNDHOLM. "Corporate Disclosure Policy and Analyst Behavior." The Accounting Review 71 (1996): 467-92.

LA PORTA, R.; F. LOPEZ-DE-SILANES; A. SHLEIFER; AND R. VISHNY. "Legal Determinants of External Finance." The Journal of Finance 52 (1997): 1131-50.

LESMOND, D.; J. OGDEN; AND C. TRZCINKA. "A New Estimate of Transaction Costs." Review of Financial Studies 12 (1999): 1113-41.

LEUZ, C. "IAS Versus US GAAP: Information Asymmetry-Based Evidence from Germany's New Market.” Journal of Accounting Research 41 (2003): 445-72. 
LEUZ, C.; D. NANDA; AND P. WYSOCKI. "Earnings Management and Investor Protection: An International Comparison.” Journal of Financial Economics 69 (2003): 505-27.

LEUZ, C., AND R. VERRECCHIA. "The Economic Consequences of Increased Disclosure." Journal of Accounting Research 38 (2000): 91-124.

LEUZ, C., AND P. WYSOCKI. "Economic Consequences of Financial Reporting and Disclosure Regulation: A Review and Suggestions for Future Research." Working paper, University of Chicago, 2008.

OHLSON, J., AND B. JUETTNER-NAUROTH. "Expected EPS and EPS Growth as Determinants of Value." Review of Accounting Studies 10 (2005): 349-65.

SLOAN, R. "Do Stock Prices Fully Reflect Information in Accruals and Cash Flows About Future Earnings?" The Accounting Review 71 (1996): 289-315.

STULZ, R. "Globalization, Corporate Finance and the Cost of Capital." Journal of Applied Corporate Finance 12 (1999): 8-25.

TAN, H.; S. WANG; AND M. WELKER. "Analyst Following and Forecast Accuracy After Mandated IFRS Adoptions.” Journal of Accounting Research 49 (2011): 1307-57.

VERRECCHIA, R. "Essays on Disclosure." Journal of Accounting and Economics 32 (2001): 91-180.

WATTS, R., AND J. ZIMMERMANN. Positive Accounting Theory. Edgewood Cliffs: Prentice Hall, 1986.

WELKER, M. "Disclosure Policy, Information Asymmetry, and Liquidity in Equity Markets." Contemporary Accounting Research 11 (1995): 801-27.

WYSOCKI, P. "Discussion of Ultimate Ownership, Income Management, and Legal and ExtraLegal Institutions." Journal of Accounting Research 42 (2004): 463-74.

YU, F. "Analyst Coverage and Earnings Management." Journal of Financial Economics 88 (2008): 245-71. 
TABLE 1

Sample Composition by Country and Year

Panel A: Accounting Standards, Listing Status, and Index Membership by Country

\begin{tabular}{|c|c|c|c|c|c|c|c|c|c|c|c|c|}
\hline \multirow[b]{2}{*}{ Country } & \multirow[b]{2}{*}{$\begin{array}{c}\text { Unique } \\
\text { Firms }\end{array}$} & \multirow[b]{2}{*}{$\begin{array}{l}\text { Firm- } \\
\text { Years }\end{array}$} & \multicolumn{2}{|c|}{ IAS/IFRS } & \multicolumn{2}{|c|}{ U.S. GAAP } & \multicolumn{2}{|c|}{ U.S. Listing } & \multicolumn{2}{|c|}{ New Markets } & \multicolumn{2}{|c|}{ Index Member } \\
\hline & & & $\begin{array}{l}\text { Firm- } \\
\text { Years }\end{array}$ & $\%$ & $\begin{array}{l}\text { Firm- } \\
\text { Years }\end{array}$ & $\%$ & $\begin{array}{l}\text { Firm- } \\
\text { Years }\end{array}$ & $\%$ & $\begin{array}{l}\text { Firm- } \\
\text { Years }\end{array}$ & $\%$ & $\begin{array}{l}\text { Firm- } \\
\text { Years }\end{array}$ & $\%$ \\
\hline Australia & 983 & 5,412 & 66 & 1.2 & 3 & 0.1 & 703 & 13.0 & 58 & 1.1 & 2,892 & 53.4 \\
\hline Austria & 131 & 974 & 223 & 22.9 & 20 & 2.1 & 93 & 9.5 & 46 & 4.7 & 221 & 22.7 \\
\hline Belgium & 171 & 1,159 & 78 & 6.7 & 8 & 0.7 & 27 & 2.3 & 0 & 0.0 & 302 & 26.1 \\
\hline Bermuda & 18 & 66 & 12 & 18.2 & 25 & 37.9 & 9 & 13.6 & 12 & 18.2 & 12 & 18.2 \\
\hline Canada & 1,277 & 7,554 & 7 & 0.1 & 122 & 1.6 & 1,458 & 19.3 & 35 & 0.5 & 2,802 & 37.1 \\
\hline China & 1,121 & 3,362 & 728 & 21.7 & 21 & 0.6 & 127 & 3.8 & 6 & 0.2 & 89 & 2.6 \\
\hline Czech Republic & 55 & 159 & 42 & 26.4 & 0 & 0.0 & 8 & 5.0 & 0 & 0.0 & 21 & 13.2 \\
\hline Denmark & 239 & 2,129 & 90 & 4.2 & 2 & 0.1 & 16 & 0.8 & 0 & 0.0 & 309 & 14.5 \\
\hline Finland & 152 & 919 & 28 & 3.0 & 0 & 0.0 & 24 & 2.6 & 0 & 0.0 & 226 & 24.6 \\
\hline France & 985 & 6,253 & 132 & 2.1 & 44 & 0.7 & 197 & 3.2 & 0 & 0.0 & 2,499 & 40.0 \\
\hline Germany & 717 & 2,972 & 759 & 25.5 & 363 & 12.2 & 101 & 3.4 & 737 & 24.8 & 567 & 19.1 \\
\hline Greece & 331 & 2,131 & 26 & 1.2 & 4 & 0.2 & 36 & 1.7 & 0 & 0.0 & 616 & 28.9 \\
\hline Hong Kong & 730 & 4,871 & 60 & 1.2 & 13 & 0.3 & 613 & 12.6 & 50 & 1.0 & 1,186 & 24.3 \\
\hline Hungary & 35 & 207 & 125 & 60.4 & 6 & 2.9 & 31 & 15.0 & 0 & 0.0 & 12 & 5.8 \\
\hline Israel & 152 & 629 & 18 & 2.9 & 158 & 25.1 & 69 & 11.0 & 26 & 4.1 & 190 & 30.2 \\
\hline Italy & 188 & 1,024 & 376 & 36.7 & 0 & 0.0 & 26 & 2.5 & 27 & 2.6 & 207 & 20.2 \\
\hline Luxembourg & 29 & 142 & 32 & 22.5 & 17 & 12.0 & 23 & 16.2 & 4 & 2.8 & 67 & 47.2 \\
\hline The Netherlands & 288 & 2,187 & 44 & 2.0 & 73 & 3.3 & 167 & 7.6 & 41 & 1.9 & 283 & 12.9 \\
\hline Norway & 240 & 1,619 & 15 & 0.9 & 12 & 0.7 & 122 & 7.5 & 0 & 0.0 & 361 & 22.3 \\
\hline Pakistan & 86 & 583 & 44 & 7.5 & 0 & 0.0 & 0 & 0.0 & 0 & 0.0 & 449 & 77.0 \\
\hline Peru & 54 & 282 & 74 & 26.2 & 4 & 1.4 & 38 & 13.5 & 0 & 0.0 & 98 & 34.8 \\
\hline Poland & 103 & 519 & 29 & 5.6 & 2 & 0.4 & 18 & 3.5 & 0 & 0.0 & 97 & 18.7 \\
\hline Portugal & 100 & 599 & 10 & 1.7 & 0 & 0.0 & 24 & 4.0 & 0 & 0.0 & 273 & 45.6 \\
\hline Russian Federation & 36 & 153 & 48 & 31.4 & 14 & 9.2 & 87 & 56.9 & 0 & 0.0 & 6 & 3.9 \\
\hline Singapore & 456 & 2,367 & 25 & 1.1 & 12 & 0.5 & 109 & 4.6 & 1,879 & 79.4 & 729 & 30.8 \\
\hline South Africa & 494 & 2,762 & 88 & 3.2 & 1 & 0.0 & 370 & 13.4 & 0 & 0.0 & 851 & 30.8 \\
\hline Sweden & 370 & 2,408 & 40 & 1.7 & 0 & 0.0 & 157 & 6.5 & 7 & 0.3 & 375 & 15.6 \\
\hline Switzerland & 283 & 2,076 & 747 & 36.0 & 30 & 1.4 & 34 & 1.6 & 8 & 0.4 & 287 & 13.8 \\
\hline Turkey & 193 & 1,100 & 180 & 16.4 & 0 & 0.0 & 25 & 2.3 & 0 & 0.0 & 656 & 59.6 \\
\hline United Kingdom & 2,154 & 12,910 & 9 & 0.1 & 13 & 0.1 & 1,144 & 8.9 & 747 & 5.8 & 5,922 & 45.9 \\
\hline Total & 12,171 & 69,528 & 4,155 & 6.0 & 967 & 1.4 & 5,856 & 8.4 & 3,683 & 5.3 & 22,605 & 32.5 \\
\hline
\end{tabular}


TABLE 1-Continued

Panel B: Accounting Standards, Listing Status, and Index Membership by Year

\begin{tabular}{|c|c|c|c|c|c|c|c|c|c|c|c|}
\hline \multirow[b]{2}{*}{ Year } & \multirow[b]{2}{*}{ Firms } & \multicolumn{2}{|c|}{ IAS/IFRS } & \multicolumn{2}{|c|}{ U.S. GAAP } & \multicolumn{2}{|c|}{ U.S. Listing } & \multicolumn{2}{|c|}{ New Markets } & \multicolumn{2}{|c|}{ Index Member } \\
\hline & & Firms & $\%$ & Firms & $\%$ & Firms & $\%$ & Firms & $\%$ & Firms & $\%$ \\
\hline 1990 & 1,225 & 26 & 2.1 & 4 & 0.3 & 112 & 9.1 & 38 & 3.1 & 476 & 38.9 \\
\hline 1991 & 1,877 & 43 & 2.3 & 8 & 0.4 & 154 & 8.2 & 43 & 2.3 & 700 & 37.3 \\
\hline 1992 & 2,371 & 59 & 2.5 & 9 & 0.4 & 179 & 7.5 & 62 & 2.6 & 838 & 35.3 \\
\hline 1993 & 2,612 & 61 & 2.3 & 11 & 0.4 & 189 & 7.2 & 61 & 2.3 & 886 & 33.9 \\
\hline 1994 & 2,983 & 92 & 3.1 & 15 & 0.5 & 226 & 7.6 & 55 & 1.8 & 982 & 32.9 \\
\hline 1995 & 3,252 & 101 & 3.1 & 17 & 0.5 & 259 & 8.0 & 89 & 2.7 & 1,080 & 33.2 \\
\hline 1996 & 3,633 & 139 & 3.8 & 23 & 0.6 & 323 & 8.9 & 133 & 3.7 & 1,214 & 33.4 \\
\hline 1997 & 4,355 & 193 & 4.4 & 25 & 0.6 & 396 & 9.1 & 157 & 3.6 & 1,401 & 32.2 \\
\hline 1998 & 4,664 & 220 & 4.7 & 31 & 0.7 & 445 & 9.5 & 169 & 3.6 & 1,569 & 33.6 \\
\hline 1999 & 5,496 & 318 & 5.8 & 59 & 1.1 & 503 & 9.2 & 232 & 4.2 & 1,837 & 33.4 \\
\hline 2000 & 5,904 & 429 & 7.3 & 94 & 1.6 & 534 & 9.0 & 348 & 5.9 & 1,983 & 33.6 \\
\hline 2001 & 6,853 & 552 & 8.1 & 163 & 2.4 & 622 & 9.1 & 579 & 8.4 & 2,212 & 32.3 \\
\hline 2002 & 7,224 & 616 & 8.5 & 161 & 2.2 & 637 & 8.8 & 660 & 9.1 & 2,342 & 32.4 \\
\hline 2003 & 7,650 & 618 & 8.1 & 157 & 2.1 & 581 & 7.6 & 494 & 6.5 & 2,215 & 29.0 \\
\hline 2004 & 7,321 & 633 & 8.6 & 163 & 2.2 & 530 & 7.2 & 381 & 5.2 & 2,082 & 28.4 \\
\hline 2005 & 2,108 & 55 & 2.6 & 27 & 1.3 & 166 & 7.9 & 182 & 8.6 & 788 & 37.4 \\
\hline Total Firm-Years & 69,528 & 4,155 & 6.0 & 967 & 1.4 & 5,856 & 8.4 & 3,683 & 5.3 & 22,605 & 32.5 \\
\hline
\end{tabular}

The sample comprises a maximum of 69,528 firm-year observations from 30 countries with fiscal year ends between January 1, 1990, and December 31, 2005, for which we have sufficient Worldscope and Datastream data to estimate our base regressions (see Table 3). We exclude fiscal years of firms that are subject to mandatory IFRS reporting. We require firms to have total assets of 10 US\$ million or more, and limit the sample to countries with at least one voluntary IAS firm-year observation. The table reports the number of unique firms as well as firm-year observations and percentages by country (Panel A) and year (Panel B) for the following indicator variables (coded as ' 1 ' if the definition applies): IAS/IFRS and U.S. GAAP indicate financial reports in accordance with the respective accounting standards. We identify firms' reporting standards based on the "accounting standards followed" field in Worldscope (field 07536), and adjust the coding for contradictory information from an extensive manual review of firms' annual reports (see the Appendix for details). U.S. Listing marks firm-years from companies whose shares are traded over-the-counter or are exchange-listed in the U.S. (see Hail and Leuz [2009]). We do not include the U.S. listing observations in the U.S. GAAP indicator. New Market observations stem from firms traded on an exchange that specializes in technology shares and other high-growth stocks, and that has listing requirements mandating or allowing financial reports in accordance with IAS/IFRS (i.e., Alternative Investment Market in the U.K., Expandi Market in Italy, Neuer Markt in Germany, Nordic Growth Market in Sweden, and Sesdaq in Singapore). The Index Member variable represents firms whose shares are constituents of national or international stock market indices as defined in Worldscope (field 05661). 
TABLE 2

Descriptive Statistics for Regression Variables across Voluntary IAS and Local GAAP Reporting Firms

\section{Panel A: Dependent Variables}

\begin{tabular}{|c|c|c|c|c|c|c|c|c|c|}
\hline Variable & Accounting Standard & $\mathrm{N}$ & Mean & Std. Dev. & $\mathrm{P} 1$ & $\mathrm{P} 25$ & Median & P75 & P99 \\
\hline \multirow[t]{2}{*}{ Price Impact } & Local GAAP & 65,373 & 2.644 & 9.903 & 0.000 & 0.028 & 0.191 & 1.191 & 49.404 \\
\hline & IAS & 4,155 & 1.556 & 6.582 & 0.001 & 0.017 & 0.099 & 0.601 & 26.257 \\
\hline \multirow[t]{2}{*}{ Bid-Ask Spread } & Local GAAP & 45,593 & 0.033 & 0.040 & 0.002 & 0.009 & 0.019 & 0.039 & 0.205 \\
\hline & IAS & 3,450 & 0.019 & 0.024 & 0.001 & 0.006 & 0.012 & 0.024 & 0.105 \\
\hline \multirow[t]{2}{*}{ Cost of Capital } & Local GAAP & 24,134 & $11,9 \%$ & $4,1 \%$ & $5,5 \%$ & $9,0 \%$ & $11,1 \%$ & $14,0 \%$ & $25,1 \%$ \\
\hline & IAS & 1,800 & $12,1 \%$ & $4,3 \%$ & $5,7 \%$ & $8,9 \%$ & $11,4 \%$ & $14,2 \%$ & $25,8 \%$ \\
\hline
\end{tabular}

Panel B: Independent Variables

\begin{tabular}{|c|c|c|c|c|c|c|c|c|c|}
\hline Variable & Accounting Standard & $\mathrm{N}$ & Mean & Std. Dev. & $\mathrm{P} 1$ & $\mathrm{P} 25$ & Median & P75 & P99 \\
\hline \multirow[t]{2}{*}{ Reporting Incentives } & Local GAAP & 63,949 & 0.031 & 0.562 & -1.326 & -0.349 & 0.041 & 0.413 & 1.255 \\
\hline & IAS & 4,127 & 0.168 & 0.567 & -1.211 & -0.203 & 0.171 & 0.571 & 1.330 \\
\hline \multirow[t]{2}{*}{ Reporting Behavior } & Local GAAP & 57,124 & -1.637 & 2.562 & -13.397 & -1.599 & -0.809 & -0.470 & -0.086 \\
\hline & IAS & 3,215 & -1.632 & 2.636 & -13.441 & -1.501 & -0.822 & -0.515 & -0.106 \\
\hline \multirow[t]{2}{*}{ Reporting Environment } & Local GAAP & 65,373 & 1.009 & 1.011 & 0.000 & 0.000 & 0.732 & 1.866 & 3.144 \\
\hline & IAS & 4,155 & 1.083 & 1.072 & 0.000 & 0.000 & 0.828 & 2.049 & 3.198 \\
\hline \multirow[t]{2}{*}{ Market Value } & Local GAAP & 65,373 & 582 & 1,496 & 4 & 37 & 122 & 410 & 8,267 \\
\hline & IAS & 4,155 & 845 & 1,752 & 6 & 72 & 238 & 721 & 9,349 \\
\hline \multirow[t]{2}{*}{ Share Turnover } & Local GAAP & 65,373 & 0.559 & 0.900 & 0.003 & 0.114 & 0.312 & 0.662 & 4.449 \\
\hline & IAS & 4,155 & 0.526 & 0.910 & 0.002 & 0.098 & 0.267 & 0.593 & 4.310 \\
\hline \multirow[t]{2}{*}{ Return Variability } & Local GAAP & 65,373 & 0.121 & 0.080 & 0.023 & 0.068 & 0.099 & 0.151 & 0.421 \\
\hline & IAS & 4,155 & 0.133 & 0.083 & 0.021 & 0.075 & 0.110 & 0.168 & 0.417 \\
\hline \multirow[t]{2}{*}{ Total Assets } & Local GAAP & 64,852 & 1,216 & 3,796 & 11 & 64 & 191 & 675 & 19,954 \\
\hline & IAS & 4,116 & 1,971 & 4,944 & 16 & 120 & 404 & 1,400 & 25,301 \\
\hline \multirow[t]{2}{*}{ Financial Leverage } & Local GAAP & 64,232 & 0.508 & 0.241 & 0.012 & 0.340 & 0.520 & 0.678 & 0.964 \\
\hline & IAS & 4,095 & 0.529 & 0.236 & 0.013 & 0.366 & 0.548 & 0.700 & 0.968 \\
\hline \multirow[t]{2}{*}{ Forecast Bias } & Local GAAP & 34,912 & 0.010 & 0.044 & -0.079 & -0.004 & 0.001 & 0.013 & 0.213 \\
\hline & IAS & 2,606 & 0.011 & 0.045 & -0.088 & -0.004 & 0.001 & 0.015 & 0.214 \\
\hline Inflation & - & 68,273 & $2.4 \%$ & $1.9 \%$ & $0.0 \%$ & $1.4 \%$ & $2.1 \%$ & $3.0 \%$ & $9.6 \%$ \\
\hline
\end{tabular}




\section{TABLE 2-Continued}

The sample comprises a maximum of 69,528 firm-year observations from 30 countries between 1990 and 2005 with financial data from Worldscope and price/volume data from Datastream (see Table 1). IAS and Local GAAP represent firm-years with financial reports in accordance with either IAS/IFRS or domestic accounting standards, based on our augmented Worldscope accounting standards classification described in the Appendix. The table reports descriptive statistics for the dependent variables (Panel A) and the continuous independent variables (Panel B) across IAS and local GAAP firm-year observations. We use three dependent variables in our primary analyses: (1) Price Impact is the yearly median of the Amihud [2002] illiquidity measure (i.e., daily absolute stock return divided by US\$ trading volume). (2) The Bid-Ask Spread is the yearly median quoted spread (i.e., difference between the bid and ask price divided by the mid-point and measured at the end of each trading day). (3) Cost of Capital is the average cost of capital estimate implied by the mean I/B/E/S analyst consensus forecasts and stock prices using the valuation models of Claus and Thomas [2001], Gebhardt, Lee and Swaminathan [2001], Easton [2004], and Ohlson and Juettner-Nauroth [2005]. See the appendix in Hail and Leuz [2006] for details on the implied cost of capital estimation procedure. In each of our regression models, we account for firms' reporting practices with one of the following three variables: (1) using factor analysis, we extract a single factor indicating the strength of firms' reporting incentives from various firm attributes (i.e., market value of equity, financial leverage, return on assets, book-to-market ratio, percent of closely-held shares, and percent of foreign sales). We then compute the level of a firm's Reporting Incentives in year $t$ as the rolling average of the raw factor scores over the years $t$ to $t$-2. Higher values denote greater reporting incentives. (2) We measure firms' actual reporting behavior as the absolute value of accruals scaled by the absolute value of cash flows from operations. We then compute the level of a firm's Reporting Behavior in year $t$ as the rolling average of the raw measures over the years $t$ to $t-2$. We multiply the metric by -1 so that higher values denote less earnings management and more transparent reporting. (3) We measure external pressure from the reporting environment by the number of analysts following the firm. For firms without coverage in I/B/E/S we set analyst following to zero. We then compute the level of a firm's Reporting Environment in year $t$ as the rolling average of the natural logs of the annual number of analysts (plus one) over the years $t$ to $t$-2. Higher values denote more external pressure. The remaining control variables are: Market Value is stock price times the number of shares outstanding (in US\$ million). Share Turnover is annual US\$ trading volume divided by market value of outstanding equity. We compute Return Variability as the annual standard deviation of monthly stock returns. Total Assets are denominated in US\$ million. Financial Leverage is computed as the ratio of total liabilities to total assets. Forecast Bias equals the one-year-ahead I/B/E/S analyst forecast error (mean forecast minus actual) scaled by lagged total assets. Inflation is the annual median of the one-year-ahead realized monthly percentage changes in a country's consumer price index as reported in Datastream. Accounting data and market values are measured as of the fiscal-year end, the dependent variables, analyst following, forecast bias, return variability and share turnover as of month +10 after the end of the fiscal year. Except for variables with natural lower or upper bounds, we truncate all variables at the first and 99th percentile. 
TABLE 3

Regression Analysis of Liquidity and Cost of Capital around Voluntary IAS Adoptions

\begin{tabular}{|c|c|c|c|c|c|c|c|c|c|}
\hline \multirow[b]{2}{*}{ Variables } & \multicolumn{3}{|c|}{$\log ($ Price Impact $)$} & \multicolumn{3}{|c|}{$\log ($ Bid-Ask Spread) } & \multicolumn{3}{|c|}{ Cost of Capital } \\
\hline & $\begin{array}{l}\text { Model 1: } \\
\text { Reporting } \\
\text { Incentives }\end{array}$ & $\begin{array}{l}\text { Model 2: } \\
\text { Reporting } \\
\text { Behavior }\end{array}$ & $\begin{array}{c}\text { Model 3: } \\
\text { Reporting } \\
\text { Environment }\end{array}$ & $\begin{array}{l}\text { Model 1: } \\
\text { Reporting } \\
\text { Incentives }\end{array}$ & $\begin{array}{l}\text { Model 2: } \\
\text { Reporting } \\
\text { Behavior }\end{array}$ & $\begin{array}{c}\text { Model 3: } \\
\text { Reporting } \\
\text { Environment }\end{array}$ & $\begin{array}{l}\text { Model 1: } \\
\text { Reporting } \\
\text { Incentives }\end{array}$ & $\begin{array}{l}\text { Model 2: } \\
\text { Reporting } \\
\text { Behavior }\end{array}$ & $\begin{array}{c}\text { Model 3: } \\
\text { Reporting } \\
\text { Environment }\end{array}$ \\
\hline IAS & $\begin{array}{l}-2.37 \\
(-0.83)\end{array}$ & $\begin{array}{l}-2.45 \\
(-0.81)\end{array}$ & $\begin{array}{c}0.51 \\
(0.18)\end{array}$ & $\begin{array}{c}3.45^{*} \\
(1.79)\end{array}$ & $\begin{array}{l}-3.36^{*} \\
(-1.84)\end{array}$ & $\begin{array}{l}5.02 * * * \\
(2.60)\end{array}$ & $\begin{array}{l}0.42 * * * \\
(3.29)\end{array}$ & $\begin{array}{c}0.20 \\
(1.30)\end{array}$ & $\begin{array}{l}0.33 * * \\
(2.26)\end{array}$ \\
\hline Reporting Variable $_{\text {Level }}$ & $\begin{array}{l}-55.96 * * * \\
(-22.17)\end{array}$ & $\begin{array}{l}-2.53 * * * \\
(-9.56)\end{array}$ & $\begin{array}{l}-24.62 * * * \\
(-22.62)\end{array}$ & $\begin{array}{l}-19.68^{* * * *} \\
(-12.54)\end{array}$ & $\begin{array}{l}-1.38 * * * \\
(-9.60)\end{array}$ & $\begin{array}{l}-8.90 * * * \\
(-12.62)\end{array}$ & $\begin{array}{c}-3.26 * * * \\
(-31.94)\end{array}$ & $\begin{array}{l}-0.13 * * * \\
(-6.80)\end{array}$ & $\begin{array}{l}-0.43 * * * \\
(-8.33)\end{array}$ \\
\hline Control Variables: & & & & & & & & & \\
\hline U.S. GAAP & $\begin{array}{c}5.33 \\
(0.90)\end{array}$ & $\begin{array}{c}4.58 \\
(0.78)\end{array}$ & $\begin{array}{c}5.94 \\
(1.00)\end{array}$ & $\begin{array}{l}-0.71 \\
(-0.20)\end{array}$ & $\begin{array}{c}0.16 \\
(0.05)\end{array}$ & $\begin{array}{c}2.89 \\
(0.82)\end{array}$ & $\begin{array}{l}-0.04 \\
(-0.12)\end{array}$ & $\begin{array}{l}-0.40 \\
(-0.99)\end{array}$ & $\begin{array}{l}-0.34 \\
(-0.87)\end{array}$ \\
\hline U.S. Listing & $\begin{array}{l}-25.97 * * * \\
(-10.24)\end{array}$ & $\begin{array}{l}-26.68 * * * \\
(-10.55)\end{array}$ & $\begin{array}{l}-25.29 * * * \\
(-9.95)\end{array}$ & $\begin{array}{l}-2.61 \\
(-1.50)\end{array}$ & $\begin{array}{l}-6.80^{* * *} \\
(-4.33)\end{array}$ & $\begin{array}{l}-1.83 \\
(-1.07)\end{array}$ & $\begin{array}{c}0.18^{*} \\
(1.78)\end{array}$ & $\begin{array}{l}-0.38^{* * * *} \\
(-3.41)\end{array}$ & $\begin{array}{l}-0.35^{* * *} \\
(-3.19)\end{array}$ \\
\hline New Markets & $\begin{array}{l}21.81 * * * \\
(5.90)\end{array}$ & $\begin{array}{l}25.54 * * * \\
(6.64)\end{array}$ & $\begin{array}{l}30.53^{* * *} \\
(8.16)\end{array}$ & $\begin{array}{l}12.19^{* * *} \\
(5.62)\end{array}$ & $\begin{array}{l}14.22 * * * \\
(6.26)\end{array}$ & $\begin{array}{l}15.35 * * * \\
(7.04)\end{array}$ & $\begin{array}{c}0.41^{*} \\
(1.86)\end{array}$ & $\begin{array}{l}0.55^{* *} \\
(2.22)\end{array}$ & $\begin{array}{l}0.59 * * \\
(2.50)\end{array}$ \\
\hline Index Member & $\begin{array}{l}-56.46^{* * * *} \\
(-30.06)\end{array}$ & $\begin{array}{l}-62.08 * * * \\
(-30.96)\end{array}$ & $\begin{array}{l}-51.98 * * * \\
(-27.97)\end{array}$ & $\begin{array}{l}-18.49 * * * \\
(-14.71)\end{array}$ & $\begin{array}{l}-20.06 * * * \\
(-16.63)\end{array}$ & $\begin{array}{l}-16.68^{* * * *} \\
(-13.26)\end{array}$ & $\begin{array}{l}-0.73 * * * \\
(-9.24)\end{array}$ & $\begin{array}{l}-1.25^{* * * *} \\
(-14.20)\end{array}$ & $\begin{array}{l}-1.11 * * * \\
(-13.20)\end{array}$ \\
\hline $\log \left(\right.$ Market Value $\left.\mathrm{t}_{\mathrm{t}-1}\right)$ & $\begin{array}{l}-82.89 * * * \\
(-93.93)\end{array}$ & $\begin{array}{l}-98.33 * * * \\
(-176.20)\end{array}$ & $\begin{array}{l}-90.71 * * * \\
(-138.60)\end{array}$ & $\begin{array}{l}-25.97 * * * \\
(-48.50)\end{array}$ & $\begin{array}{l}-31.15^{* * * *} \\
(-94.50)\end{array}$ & $\begin{array}{l}-28.76^{* * *} \\
(-71.39)\end{array}$ & - & - & - \\
\hline $\log \left(\right.$ Share Turnover $\left.{ }_{t-1}\right)$ & $\begin{array}{l}-66.28 * * * \\
(-106.96)\end{array}$ & $\begin{array}{l}-66.86^{* * *} \\
(-105.60)\end{array}$ & $\begin{array}{l}-63.80^{* * *} \\
(-104.09)\end{array}$ & $\begin{array}{l}-21.53 * * * \\
(-57.98)\end{array}$ & $\begin{array}{l}-20.94 * * * \\
(-55.41)\end{array}$ & $\begin{array}{l}-20.84 * * * \\
(-56.48)\end{array}$ & - & - & - \\
\hline $\log \left(\right.$ Return Variability $\left.y_{\mathrm{t}-1}\right)$ & $\begin{array}{l}45.81 * * * \\
(37.24)\end{array}$ & $\begin{array}{l}43.77 * * * \\
(33.27)\end{array}$ & $\begin{array}{l}46.21 * * * \\
(37.87)\end{array}$ & $\begin{array}{l}33.21 * * * \\
(41.49)\end{array}$ & $\begin{array}{l}28.31 * * * \\
(34.74)\end{array}$ & $\begin{array}{l}33.55^{* * * *} \\
(42.38)\end{array}$ & - & - & - \\
\hline Log(Total Assets) & - & - & - & - & - & - & $\begin{array}{l}0.29 * * * \\
(9.39)\end{array}$ & $\begin{array}{l}-0.25 * * * \\
(-9.07)\end{array}$ & $\begin{array}{l}-0.12 * * * \\
(-4.13)\end{array}$ \\
\hline Financial Leverage & - & - & - & - & - & - & $\begin{array}{l}3.92 * * * \\
(21.29)\end{array}$ & $\begin{array}{l}3.90^{* * * *} \\
(18.88)\end{array}$ & $\begin{array}{l}3.43^{* * *} \\
(17.56)\end{array}$ \\
\hline Return Variability & - & - & - & - & - & - & $\begin{array}{l}6.25^{* * *} \\
(10.05)\end{array}$ & $\begin{array}{l}6.53^{* * * *} \\
(9.64)\end{array}$ & $\begin{array}{l}7.11^{* * *} \\
(11.21)\end{array}$ \\
\hline Forecast Bias & - & - & - & - & - & - & $\begin{array}{l}19.68^{* * *} \\
(19.38)\end{array}$ & $\begin{array}{l}17.98^{* * *} \\
(17.14)\end{array}$ & $\begin{array}{l}18.57^{* * *} \\
(18.62)\end{array}$ \\
\hline Inflation & - & - & - & - & - & - & $\begin{array}{l}28.06^{* * *} \\
(13.19)\end{array}$ & $\begin{array}{l}24.80^{* * *} \\
(10.46)\end{array}$ & $\begin{array}{l}26.55^{* * *} \\
(12.03)\end{array}$ \\
\hline $\begin{array}{l}\text { Country-, Year-, and } \\
\text { Industry-Fixed Effects }\end{array}$ & Yes & Yes & Yes & Yes & Yes & Yes & Yes & Yes & Yes \\
\hline $\mathrm{R}^{2}$ & $81.4 \%$ & $81.9 \%$ & $81.4 \%$ & $73.1 \%$ & $75.9 \%$ & $73.3 \%$ & $35.9 \%$ & $30.6 \%$ & $30.4 \%$ \\
\hline \# Observations & 68,076 & 60,339 & 69,528 & 47,985 & 42,652 & 49,043 & 25,260 & 23,689 & 25,934 \\
\hline \# Unique Firms & 12,024 & 10,938 & 12,171 & 9,722 & 8,825 & 9,838 & 5,881 & 5,439 & 6,051 \\
\hline \# Countries & 30 & 30 & 30 & 24 & 24 & 24 & 29 & 29 & 29 \\
\hline
\end{tabular}




\section{TABLE 3-Continued}

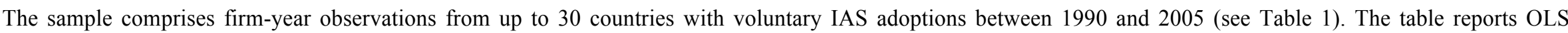

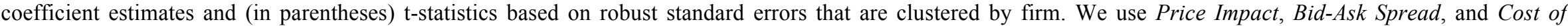

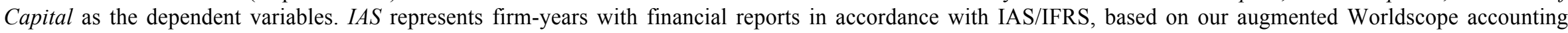

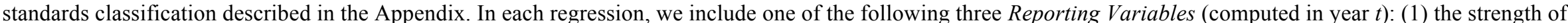

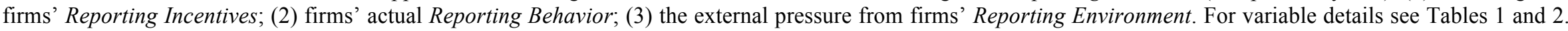

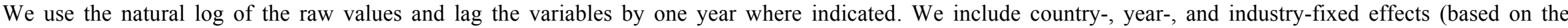

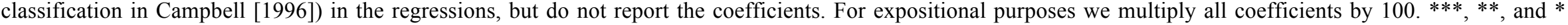
indicate statistical significance at the $1 \%, 5 \%$, and $10 \%$ levels (two-tailed). 
TABLE 4

Descriptive Statistics for Serious and Label Voluntary IAS Adoptions

Panel A: Descriptive Statistics for the Reporting Variables Used to Partition the Voluntary IAS Firms into Serious and Label Adopters

\begin{tabular}{|c|c|c|c|c|c|c|c|}
\hline \multicolumn{2}{|l|}{ Variables } & $\mathrm{N}$ & Mean & Std. Dev. & $\mathrm{P} 1$ & Median & P99 \\
\hline \multicolumn{8}{|c|}{ Split by Changes in Reporting Incentives: } \\
\hline \multirow[t]{2}{*}{ Label Adopters } & Pre-Adoption Level & 270 & 0.330 & 0.501 & -1.018 & 0.356 & 1.314 \\
\hline & $\Delta$ around Adoption & 270 & -0.264 & 0.331 & -1.582 & -0.175 & 0.037 \\
\hline \multirow[t]{2}{*}{ Serious Adopters } & Pre-Adoption Level & 257 & 0.118 & 0.573 & -1.198 & 0.094 & 1.256 \\
\hline & $\Delta$ around Adoption & 257 & 0.359 & 0.293 & 0.047 & 0.277 & 1.410 \\
\hline \multirow[t]{2}{*}{ Total } & Pre-Adoption Level & 527 & 0.227 & 0.547 & -1.163 & 0.220 & 1.276 \\
\hline & $\Delta$ around Adoption & 527 & 0.040 & 0.441 & -1.333 & 0.039 & 1.285 \\
\hline \multicolumn{8}{|c|}{ Split by Changes in Reporting Behavior: } \\
\hline \multirow[t]{2}{*}{ Label Adopters } & Pre-Adoption Level & 241 & -0.786 & 0.677 & -3.903 & -0.661 & -0.042 \\
\hline & $\Delta$ around Adoption & 241 & -1.638 & 3.703 & -19.852 & -0.459 & -0.004 \\
\hline \multirow[t]{2}{*}{ Serious Adopters } & Pre-Adoption Level & 229 & -2.240 & 3.139 & -15.395 & -0.972 & -0.197 \\
\hline & $\Delta$ around Adoption & 229 & 1.523 & 2.922 & 0.020 & 0.302 & 14.421 \\
\hline \multirow[t]{2}{*}{ Total } & Pre-Adoption Level & 470 & -1.494 & 2.356 & -14.654 & -0.763 & -0.097 \\
\hline & $\Delta$ around Adoption & 470 & -0.098 & 3.697 & -16.629 & -0.003 & 13.587 \\
\hline \multicolumn{8}{|c|}{ Split by Changes in Reporting Environment: } \\
\hline \multirow[t]{2}{*}{ Label Adopters } & Pre-Adoption Level & 249 & 1.637 & 0.920 & 0.231 & 1.609 & 3.219 \\
\hline & $\Delta$ around Adoption & 249 & -0.648 & 0.524 & -2.193 & -0.475 & -0.024 \\
\hline \multirow[t]{2}{*}{ Serious Adopters } & Pre-Adoption Level & 338 & 0.594 & 0.909 & 0.000 & 0.000 & 3.119 \\
\hline & $\Delta$ around Adoption & 338 & 0.429 & 0.635 & 0.000 & 0.086 & 2.556 \\
\hline \multirow[t]{2}{*}{ Total } & Pre-Adoption Level & 587 & 1.037 & 1.049 & 0.000 & 0.693 & 3.178 \\
\hline & $\Delta$ around Adoption & 587 & -0.028 & 0.795 & -2.042 & 0.000 & 2.533 \\
\hline
\end{tabular}


TABLE 4-Continued

Panel B: Distribution of Serious and Label Voluntary IAS Adopters by Country

\begin{tabular}{|c|c|c|c|c|c|c|c|c|c|}
\hline \multirow{2}{*}{$\begin{array}{l}\text { (Number of } \\
\text { Unique Firms) } \\
\text { Country }\end{array}$} & \multicolumn{3}{|c|}{$\begin{array}{l}\text { Split by Changes in } \\
\text { Reporting Incentives }\end{array}$} & \multicolumn{3}{|c|}{$\begin{array}{l}\text { Split by Changes in } \\
\text { Reporting Behavior }\end{array}$} & \multicolumn{3}{|c|}{$\begin{array}{l}\text { Split by Changes in } \\
\text { Reporting Environment }\end{array}$} \\
\hline & Label & Serious & Total & Label & Serious & Total & Label & Serious & Total \\
\hline Australia & 2 & 2 & 4 & 0 & 3 & 3 & 2 & 2 & 4 \\
\hline Austria & 22 & 16 & 38 & 17 & 14 & 31 & 18 & 25 & 43 \\
\hline Belgium & 5 & 7 & 12 & 4 & 9 & 13 & 8 & 5 & 13 \\
\hline Bermuda & 0 & 2 & 2 & 0 & 1 & 1 & 0 & 2 & 2 \\
\hline Canada & 0 & 0 & 0 & 1 & 0 & 1 & 0 & 1 & 1 \\
\hline China & 21 & 20 & 41 & 3 & 4 & 7 & 4 & 40 & 44 \\
\hline Czech Republic & 1 & 0 & 1 & 1 & 0 & 1 & 1 & 0 & 1 \\
\hline Denmark & 9 & 7 & 16 & 11 & 5 & 16 & 9 & 9 & 18 \\
\hline Finland & 2 & 3 & 5 & 2 & 4 & 6 & 5 & 3 & 8 \\
\hline France & 7 & 19 & 26 & 7 & 21 & 28 & 11 & 18 & 29 \\
\hline Germany & 80 & 60 & 140 & 83 & 66 & 149 & 67 & 97 & 164 \\
\hline Greece & 4 & 1 & 5 & 2 & 2 & 4 & 3 & 3 & 6 \\
\hline Hong Kong & 2 & 1 & 3 & 1 & 3 & 4 & 2 & 3 & 5 \\
\hline Hungary & 2 & 2 & 4 & 3 & 2 & 5 & 3 & 3 & 6 \\
\hline Israel & 0 & 1 & 1 & 1 & 0 & 1 & 0 & 1 & 1 \\
\hline Italy & 15 & 19 & 34 & 19 & 10 & 29 & 14 & 20 & 34 \\
\hline Luxembourg & 2 & 1 & 3 & 3 & 0 & 3 & 0 & 3 & 3 \\
\hline The Netherlands & 0 & 4 & 4 & 2 & 1 & 3 & 0 & 5 & 5 \\
\hline Norway & 1 & 0 & 1 & 1 & 0 & 1 & 1 & 0 & 1 \\
\hline Pakistan & 4 & 4 & 8 & 2 & 5 & 7 & 3 & 5 & 8 \\
\hline Peru & 12 & 2 & 14 & 8 & 1 & 9 & 6 & 8 & 14 \\
\hline Poland & 2 & 0 & 2 & 2 & 1 & 3 & 3 & 1 & 4 \\
\hline Portugal & 1 & 3 & 4 & 1 & 2 & 3 & 1 & 3 & 4 \\
\hline Russian Federation & 1 & 3 & 4 & 0 & 3 & 3 & 1 & 4 & 5 \\
\hline South Africa & 7 & 8 & 15 & 7 & 8 & 15 & 6 & 10 & 16 \\
\hline Sweden & 0 & 2 & 2 & 2 & 2 & 4 & 1 & 2 & 3 \\
\hline Switzerland & 36 & 43 & 79 & 29 & 38 & 67 & 33 & 48 & 81 \\
\hline Turkey & 32 & 27 & 59 & 29 & 24 & 53 & 47 & 17 & 64 \\
\hline Total & 270 & 257 & 527 & 241 & 229 & 470 & 249 & 338 & 587 \\
\hline
\end{tabular}


TABLE 4-Continued

Panel C: Distribution of Serious and Label Voluntary IAS Adopters by Year

\begin{tabular}{|c|c|c|c|c|c|c|c|c|c|}
\hline \multirow{2}{*}{$\begin{array}{l}\text { (Number of } \\
\text { Unique Firms) } \\
\text { Year }\end{array}$} & \multicolumn{3}{|c|}{$\begin{array}{l}\text { Split by Changes in } \\
\text { Reporting Incentives }\end{array}$} & \multicolumn{3}{|c|}{$\begin{array}{l}\text { Split by Changes in } \\
\text { Reporting Behavior }\end{array}$} & \multicolumn{3}{|c|}{$\begin{array}{c}\text { Split by Changes in } \\
\text { Reporting Environment }\end{array}$} \\
\hline & Label & Serious & Total & Label & Serious & Total & Label & Serious & Total \\
\hline 1990 & 1 & 7 & 8 & 3 & 5 & 8 & 1 & 6 & 7 \\
\hline 1991 & 3 & 2 & 5 & 2 & 2 & 4 & 0 & 5 & 5 \\
\hline 1992 & 5 & 13 & 18 & 3 & 13 & 16 & 4 & 18 & 22 \\
\hline 1993 & 4 & 11 & 15 & 3 & 9 & 12 & 1 & 14 & 15 \\
\hline 1994 & 5 & 9 & 14 & 6 & 7 & 13 & 5 & 7 & 12 \\
\hline 1995 & 10 & 4 & 14 & 2 & 9 & 11 & 2 & 10 & 12 \\
\hline 1996 & 6 & 9 & 15 & 2 & 6 & 8 & 7 & 8 & 15 \\
\hline 1997 & 13 & 13 & 26 & 9 & 7 & 16 & 10 & 20 & 30 \\
\hline 1998 & 20 & 11 & 31 & 19 & 10 & 29 & 16 & 21 & 37 \\
\hline 1999 & 41 & 23 & 64 & 38 & 21 & 59 & 34 & 43 & 77 \\
\hline 2000 & 45 & 20 & 65 & 39 & 21 & 60 & 38 & 41 & 79 \\
\hline 2001 & 33 & 14 & 47 & 26 & 16 & 42 & 29 & 24 & 53 \\
\hline 2002 & 41 & 26 & 67 & 33 & 30 & 63 & 27 & 44 & 71 \\
\hline 2003 & 32 & 42 & 74 & 31 & 33 & 64 & 46 & 36 & 82 \\
\hline 2004 & 11 & 53 & 64 & 25 & 40 & 65 & 29 & 41 & 70 \\
\hline Total & 270 & 257 & 527 & 241 & 229 & 470 & 249 & 338 & 587 \\
\hline $\begin{array}{l}\text { \% of Total in } \\
\text { pre-1998 Period }\end{array}$ & $17.4 \%$ & $26.5 \%$ & & $12.4 \%$ & $25.3 \%$ & & $12.0 \%$ & $26.0 \%$ & \\
\hline $\begin{array}{l}\% \text { of Total in } \\
\text { post- } 1997 \text { Period }\end{array}$ & $82.6 \%$ & $73.5 \%$ & & $87.6 \%$ & $74.7 \%$ & & $88.0 \%$ & $74.0 \%$ & \\
\hline
\end{tabular}

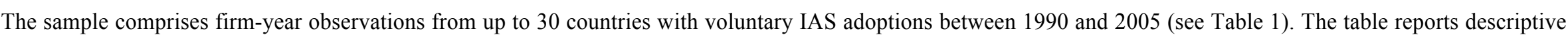

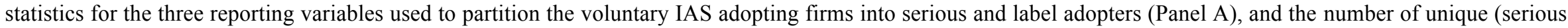

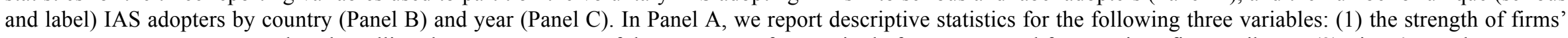

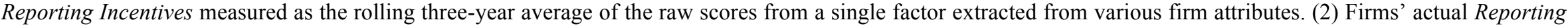

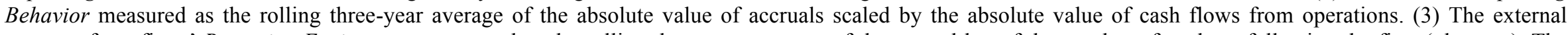

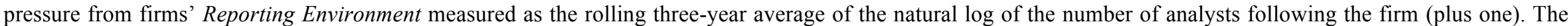

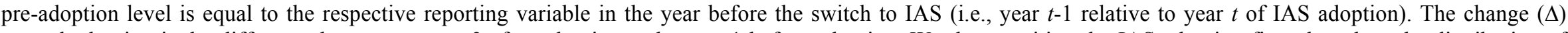



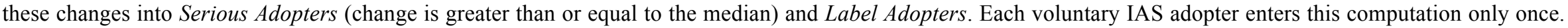
Note that due to additional data restrictions the number of unique voluntary IAS firms is lower in the later regression analyses. 
TABLE 5

Univariate Analysis of Liquidity and Cost of Capital around Serious and Label Voluntary IAS Adoptions

(Median Values

and Number of

Observations

\begin{tabular}{ccc}
\multicolumn{3}{c}{ Split by Changes in } \\
Reporting Incentives \\
\hline Label & Serious & Difference \\
Adopters & Adopters & $(2)-(1)$
\end{tabular}

(1)

(2)

Panel A: Price Impact

IAS

(a)

Local GAAP

(b)

Difference (a) - (b)

\begin{tabular}{|cc|c|}
\hline 0.111 & & 0.046 \\
1,060 & & 880 \\
\hline \multicolumn{3}{|c|}{0.185} \\
\multicolumn{3}{|c|}{63,812} \\
\hline
\end{tabular}

$-0.065^{* * *}$

$-0.074 * * * \quad-0.139 * * *$

Panel B: Bid-Ask Spread

IAS

(a)

Local GAAP

(b)

Difference $(a)-(b)$

\begin{tabular}{|c|c|}
\hline 0.012 & 0.008 \\
\hline 877 & 717 \\
\hline \multicolumn{2}{|c|}{0.019} \\
\hline \multicolumn{2}{|c|}{44,461} \\
\hline
\end{tabular}

$-0.004 * * *$

\begin{tabular}{|c|c|}
\hline $\begin{array}{c}0.012 \\
762\end{array}$ & $\begin{array}{c}0.010 \\
653\end{array}$ \\
\hline \multicolumn{2}{|c|}{0.019} \\
39,857 \\
\hline$-0.007 * * * \quad-0.009 * * *$
\end{tabular}

$-0.002 * * *$

\begin{tabular}{|c|c|}
\hline $11.4 \%$ & $11.0 \%$ \\
\hline 394 & 440 \\
\hline \multicolumn{2}{|c|}{$11.0 \%$} \\
\hline \multicolumn{2}{|c|}{22,080} \\
\hline $0.4 \%$ & $0.0 \%$ \\
\hline
\end{tabular}

\begin{tabular}{|c|c|}
\hline 0.011 & 0.010 \\
\hline 771 & 989 \\
\hline \multicolumn{2}{|c|}{0.019} \\
\hline \multicolumn{2}{|c|}{45,517} \\
\hline
\end{tabular}

$-0.001 * * *$

Split by Changes in Reporting Environment

$\begin{array}{ccc}\text { Label } & \text { Serious } & \text { Difference } \\ \text { Adopters } & \text { Adopters } & (2)-(1)\end{array}$

(1)

(2)

\begin{tabular}{|cc|r|}
\hline $\begin{array}{c}0.090 \\
889\end{array}$ & & 0.085 \\
& & 1,262 \\
\hline \multicolumn{3}{|c|}{0.191} \\
\multicolumn{3}{|c|}{65,259} \\
\hline
\end{tabular}

$-0.005$

$-0.101 * * * \quad-0.106^{* * *}$

$-0.008 * * * \quad-0.009 * * *$

$-0.4 \%$

\begin{tabular}{|c|c|}
\hline $10.8 \%$ & $11.6 \%$ \\
\hline 330 & 576 \\
\hline \multicolumn{2}{|c|}{$11.1 \%$} \\
\hline \multicolumn{2}{|c|}{24,078} \\
\hline$-0.3 \%$ & $0.5 \% *$ \\
\hline
\end{tabular}

(a)

Local GAAP

(b)

Difference (a) - (b)

\begin{tabular}{|c|c|}
\hline $\begin{array}{c}12.0 \% \\
393\end{array}$ & $\begin{array}{c}10.7 \% \\
437\end{array}$ \\
\hline \multicolumn{2}{|c|}{$11.1 \%$} \\
23,423 \\
\hline $0.9 \% * * *$ & $-0.4 \% * *$ \\
\hline
\end{tabular}

$-1.3 \% * * *$

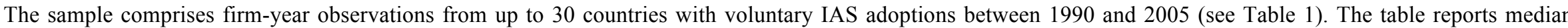

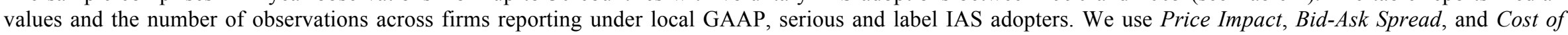

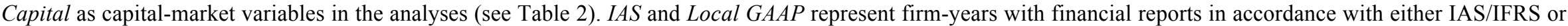

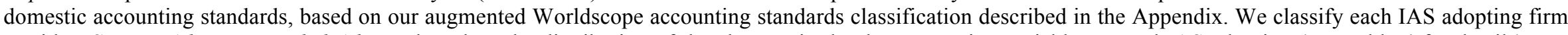

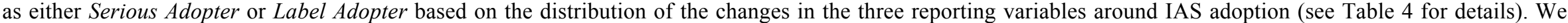

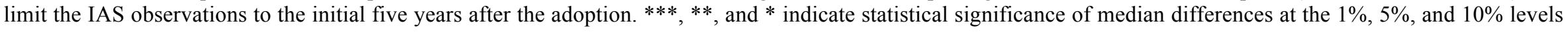
(two-tailed), based on a Wilcoxon rank sum test. 
TABLE 6

Regression Analysis of Liquidity and Cost of Capital around Serious and Label Voluntary IAS Adoptions

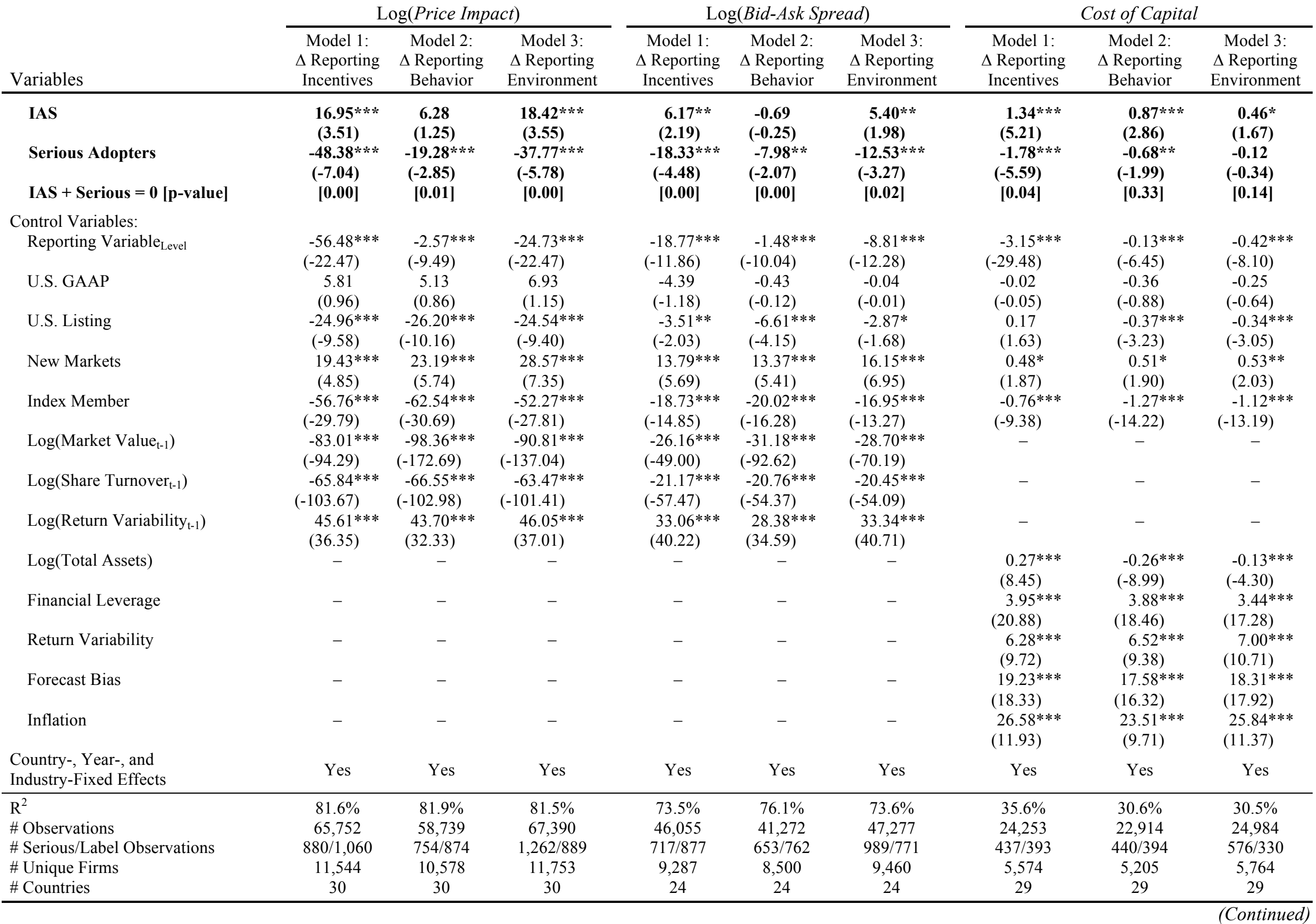




\section{TABLE 6-Continued}

The sample comprises firm-year observations from up to 30 countries with voluntary IAS adoptions between 1990 and 2005 (see Table 1). The table reports OLS coefficient estimates and (in parentheses) t-statistics based on robust standard errors that are clustered by firm. It also reports p-values [in brackets] from an F-test indicating joint statistical significance of the coefficients on IAS and Serious Adopters. We use Price Impact, Bid-Ask Spread, and Cost of Capital as the dependent variables. IAS represents firm-years with financial reports in accordance with IAS/IFRS, based on our augmented Worldscope accounting standards classification described in the Appendix. In each regression, we include one of the following three Reporting Variables (computed in year $t$, except for IAS adopting firms, for which we use the mean of the respective metric in the years before IAS adoption): (1) the strength of firms' Reporting Incentives; (2) firms' actual Reporting Behavior; (3) the external pressure from firms' Reporting Environment. We further classify each IAS adopting firm as either serious (i.e., Serious Adopters variable set equal to '1') or label adopter (i.e., Serious Adopters variable set equal to ' 0 ') based on the distribution of the changes $(\Delta)$ in the three reporting variables around IAS adoption (see Table 4 for details). We limit the IAS observations to the initial five years after the adoption. For variable details see Tables 1 and 2 . We use the natural log of the raw values and lag the variables by one year where indicated. We include country-, year-, and industry-fixed effects (based on the classification in Campbell [1996]) in the regressions, but do not report the coefficients. For expositional purposes we multiply all coefficients by $100 . * * *, * *$, and $*$ indicate statistical significance at the $1 \%$, $5 \%$, and $10 \%$ levels (two-tailed). 
TABLE 7

Sensitivity Analyses: Heterogeneity in the Accounting Standards and Mandatory IFRS Adoption

Panel A: Capital Market Effects around Serious and Label Voluntary IAS Adoptions for Strict IAS Definition After 1998 (Requiring Auditor Attestation)

\begin{tabular}{|c|c|c|c|c|c|c|c|c|c|}
\hline \multirow[b]{2}{*}{ Variables } & \multicolumn{3}{|c|}{$\log ($ Price Impact $)$} & \multicolumn{3}{|c|}{ Log(Bid-Ask Spread) } & \multicolumn{3}{|c|}{ Cost of Capital } \\
\hline & $\begin{array}{c}\text { Model 1: } \\
\Delta \text { Reporting } \\
\text { Incentives }\end{array}$ & $\begin{array}{c}\text { Model 2: } \\
\Delta \text { Reporting } \\
\text { Behavior }\end{array}$ & $\begin{array}{c}\text { Model 3: } \\
\Delta \text { Reporting } \\
\text { Environment }\end{array}$ & $\begin{array}{c}\text { Model 1: } \\
\Delta \text { Reporting } \\
\text { Incentives }\end{array}$ & $\begin{array}{c}\text { Model 2: } \\
\Delta \text { Reporting } \\
\text { Behavior }\end{array}$ & $\begin{array}{c}\text { Model 3: } \\
\Delta \text { Reporting } \\
\text { Environment }\end{array}$ & $\begin{array}{c}\text { Model 1: } \\
\Delta \text { Reporting } \\
\text { Incentives }\end{array}$ & $\begin{array}{c}\text { Model 2: } \\
\Delta \text { Reporting } \\
\text { Behavior }\end{array}$ & $\begin{array}{c}\text { Model 3: } \\
\Delta \text { Reporting } \\
\text { Environment }\end{array}$ \\
\hline IAS & $\begin{array}{l}19.05 * * * \\
(3.14)\end{array}$ & $\begin{array}{c}8.17 \\
(1.31)\end{array}$ & $\begin{array}{l}14.40 * * \\
(2.25)\end{array}$ & $\begin{array}{l}12.90 * * * \\
(3.53)\end{array}$ & $\begin{array}{c}4.77 \\
(1.42)\end{array}$ & $\begin{array}{l}10.27 * * * \\
(3.03)\end{array}$ & $\begin{array}{l}1.45 * * * \\
(4.62)\end{array}$ & $\begin{array}{l}1.23 * * * \\
(3.24)\end{array}$ & $\begin{array}{l}0.71 * * \\
(2.21)\end{array}$ \\
\hline Serious Adopters & $-48.04 * * *$ & $-18.69 * *$ & $\begin{array}{l}-36.18 * * * \\
(-4.45)\end{array}$ & $\begin{array}{l}-23.79 * * * \\
(-4.59)\end{array}$ & $-10.88 * *$ & $\begin{array}{l}-16.73 * * * \\
(-3.45)\end{array}$ & $\begin{array}{l}-1.93 * * * \\
(-4.50)\end{array}$ & $\begin{array}{l}-1.54 * * * \\
(-3.40)\end{array}$ & $\begin{array}{l}-0.51 \\
(-1.09)\end{array}$ \\
\hline IAS + Serious $=0$ [p-value $]$ & {$[0.00]$} & {$[0.12]$} & {$[0.00]$} & {$[0.01]$} & {$[0.10]$} & {$[0.10]$} & {$[0.14]$} & {$[0.29]$} & {$[0.57]$} \\
\hline $\begin{array}{l}\text { Control Variables, Country-, Year-, } \\
\text { and Industry-Fixed Effects }\end{array}$ & Yes & Yes & Yes & Yes & Yes & Yes & Yes & Yes & Yes \\
\hline $\mathrm{R}^{2}$ & $81.1 \%$ & $81.5 \%$ & $81.1 \%$ & $76.2 \%$ & $78.8 \%$ & $76.4 \%$ & $42.4 \%$ & $37.8 \%$ & $37.3 \%$ \\
\hline \# Observations & 32,102 & 29,794 & 32,823 & 24,204 & 22,474 & 24,758 & 8,117 & 7,910 & 8,453 \\
\hline \# Serious/Label Observations & $444 / 570$ & $402 / 517$ & $558 / 576$ & $383 / 532$ & $387 / 484$ & $493 / 536$ & $158 / 214$ & $192 / 193$ & $227 / 196$ \\
\hline \# Unique Firms & 7,654 & 7,126 & 7,793 & 6,074 & 5,657 & 6,190 & 2,605 & 2,456 & 2,696 \\
\hline \# Countries & 25 & 25 & 25 & 20 & 20 & 20 & 23 & 23 & 23 \\
\hline
\end{tabular}

Panel B: Capital Market Effects around Serious and Label Mandatory IFRS Adoptions

\begin{tabular}{|c|c|c|c|c|c|c|c|c|c|}
\hline \multirow[b]{2}{*}{ Variables } & \multicolumn{3}{|c|}{$\log ($ Price Impact $)$} & \multicolumn{3}{|c|}{$\log ($ Bid-Ask Spread $)$} & \multicolumn{3}{|c|}{ Cost of Capital } \\
\hline & $\begin{array}{c}\text { Model 1: } \\
\Delta \text { Reporting } \\
\text { Incentives }\end{array}$ & $\begin{array}{c}\text { Model 2: } \\
\Delta \text { Reporting } \\
\text { Behavior }\end{array}$ & $\begin{array}{c}\text { Model 3: } \\
\Delta \text { Reporting } \\
\text { Environment }\end{array}$ & $\begin{array}{c}\text { Model 1: } \\
\Delta \text { Reporting } \\
\text { Incentives }\end{array}$ & $\begin{array}{c}\text { Model 2: } \\
\Delta \text { Reporting } \\
\text { Behavior }\end{array}$ & $\begin{array}{c}\text { Model 3: } \\
\Delta \text { Reporting } \\
\text { Environment }\end{array}$ & $\begin{array}{c}\text { Model 1: } \\
\Delta \text { Reporting } \\
\text { Incentives }\end{array}$ & $\begin{array}{c}\text { Model 2: } \\
\Delta \text { Reporting } \\
\text { Behavior } \\
\end{array}$ & $\begin{array}{c}\text { Model 3: } \\
\Delta \text { Reporting } \\
\text { Environment }\end{array}$ \\
\hline IFRS & $\begin{array}{l}39.95 * * * \\
(10.64)\end{array}$ & $\begin{array}{l}20.39 * * * \\
(5.20)\end{array}$ & $\begin{array}{l}\text { 37.16*** } \\
(\mathbf{8 . 3 8 )}\end{array}$ & $\begin{array}{l}13.90 * * * \\
(7.09)\end{array}$ & $\begin{array}{l}8.78 * * * \\
(4.59)\end{array}$ & $\begin{array}{l}9.41 * * * \\
(4.05)\end{array}$ & $\begin{array}{c}0.25 \\
(1.57)\end{array}$ & $\begin{array}{c}0.05 \\
(0.30)\end{array}$ & $\begin{array}{c}0.20 \\
(1.05)\end{array}$ \\
\hline $\begin{array}{l}\text { Serious Adopters } \\
\text { IFRS }+ \text { Serious }=0 \text { [p-value }]\end{array}$ & $\begin{array}{c}-67.53 * * * \\
(-14.84) \\
{[0.00]}\end{array}$ & $\begin{array}{l}-19.44 * * * \\
(-4.09) \\
{[0.80]}\end{array}$ & $\begin{array}{l}-38.43 * * * \\
(-7.94) \\
{[0.69]}\end{array}$ & $\begin{array}{c}-25.83 * * * \\
(-10.48) \\
{[0.00]}\end{array}$ & $\begin{array}{l}-12.65 * * * \\
(-5.06) \\
{[0.05]}\end{array}$ & $\begin{array}{l}-10.63 * * * \\
(-4.05) \\
{[0.45]}\end{array}$ & $\begin{array}{l}-1.11 * * * \\
(-5.81) \\
{[0.00]}\end{array}$ & $\begin{array}{c}-0.19 \\
(-0.95) \\
{[0.41]}\end{array}$ & $\begin{array}{c}-0.43^{* *} \\
(-2.17) \\
{[0.10]}\end{array}$ \\
\hline $\begin{array}{l}\text { Control Variables, Country-, Year-, } \\
\text { and Industry-Fixed Effects }\end{array}$ & Yes & Yes & Yes & Yes & Yes & Yes & Yes & Yes & Yes \\
\hline $\mathrm{R}^{2}$ & $85.6 \%$ & $85.7 \%$ & $85.9 \%$ & $77.2 \%$ & $78.1 \%$ & $77.6 \%$ & $36.5 \%$ & $33.9 \%$ & $33.4 \%$ \\
\hline \# Observations & 22,421 & 21,375 & 23,964 & 21,709 & 20,726 & 23,280 & 6,897 & 6,960 & 7,260 \\
\hline \# Serious/Label Observations & $1,551 / 1,516$ & $1,540 / 1,551$ & $2,443 / 983$ & $1,493 / 1,465$ & $1,495 / 1,499$ & $2,384 / 934$ & $510 / 502$ & $555 / 467$ & $647 / 423$ \\
\hline \# Unique Firms & 6,825 & 6,491 & 7,252 & 6,590 & 6,258 & 7,012 & 2,806 & 2,801 & 2,940 \\
\hline \# Countries & 26 & 26 & 26 & 23 & 23 & 23 & 23 & 23 & 23 \\
\hline
\end{tabular}




\section{TABLE 7-Continued}

The sample comprises firm-year observations from up to 25 countries with voluntary IAS adoptions between 1998 and 2005 in Panel A, and from up to 26 countries with mandatory IFRS adoption by the end of 2005 (covering the years 2002 to 2005) in Panel B. The table reports only the OLS coefficients (t-statistics, clustered by firm) of the IAS and Serious Adopters (IFRS and Serious Adopters) variables, but the full set of controls and fixed effects is included. It also reports p-values [in brackets] from an F-test indicating joint statistical significance of the two variables. We use Price Impact, Bid-Ask Spread, and Cost of Capital as the dependent variables. In Panel A, IAS represents firm-years with financial reports in accordance with IAS/IFRS, based on our augmented Worldscope accounting standards classification described in the Appendix. In addition, we require the following two criteria to ensure proper IAS/IFRS reporting by the treatment firms: (1) we limit the sample to firm-years from 1998 onward, i.e., the year the IASC completed a major revision of all its core standards, and (2) we only include IAS adopting firms for which compliance with IAS/IFRS reporting in the three years following the switch is attested by the auditor in the audit opinion footnote (based on our manual inspection of the firm's financial reports). In Panel B, IFRS represents firm-years ending on or after the local date for mandated IFRS reporting (see Daske et al. [2008]), and applies only to firms that never reported under IAS/IFRS before (i.e., we exclude voluntary IAS adopter firms). We use the same three Reporting Variables as controls and to partition the mandatory IFRS adopting firms into serious and label adopters as in the voluntary IAS analyses. For details on the regression specification and the serious versus label classification see Table 6 . For variable details see Tables 1 and 2 . For expositional purposes we multiply all coefficients by $100 . * * *, * *$, and

* indicate statistical significance at the $1 \%, 5 \%$, and $10 \%$ levels (two-tailed). 
TABLE 8

Additional Sensitivity Analyses for the Capital Market Effects around Serious and Label Voluntary IAS Adoptions

\begin{tabular}{|c|c|c|c|}
\hline Variables & $\begin{array}{c}\text { Split by } \\
\Delta \text { Reporting } \\
\text { Incentives }\end{array}$ & $\begin{array}{c}\text { Split by } \\
\Delta \text { Reporting } \\
\text { Behavior }\end{array}$ & $\begin{array}{c}\text { Split by } \\
\Delta \text { Reporting } \\
\text { Environment }\end{array}$ \\
\hline \multicolumn{4}{|l|}{ Panel A: Alternative Dependent Variables } \\
\hline \multicolumn{4}{|l|}{ (1) Log(Total Trading Costs) } \\
\hline IAS & $\begin{array}{l}-9.11 * * * \\
(-2.93)\end{array}$ & $\begin{array}{c}-4.82 \\
(-1.62)\end{array}$ & $\begin{array}{c}-6.49^{*} \\
(-1.77)\end{array}$ \\
\hline Serious Adopters & $\begin{array}{l}-7.80^{*} \\
(-1.87)\end{array}$ & $\begin{array}{l}-7.57^{*} \\
(-1.72)\end{array}$ & $\begin{array}{l}-10.60^{* *} \\
(-2.48)\end{array}$ \\
\hline IAS + Serious $=0[p$-value $]$ & {$[0.00]$} & {$[0.00]$} & {$[0.00]$} \\
\hline \multicolumn{4}{|l|}{ (2) Zero Returns } \\
\hline IAS & $\begin{array}{l}-2.49 * * * \\
(-4.05)\end{array}$ & $\begin{array}{l}-2.16^{* * *} \\
(-3.26)\end{array}$ & $\begin{array}{l}-1.57^{* *} \\
(-2.15)\end{array}$ \\
\hline Serious Adopters & $\begin{array}{l}-0.22 \\
(-0.25)\end{array}$ & $\begin{array}{l}-1.19 \\
(-1.31)\end{array}$ & $\begin{array}{l}-2.03^{* *} \\
(-2.32)\end{array}$ \\
\hline IAS + Serious $=0[p-v a l u e]$ & {$[0.00]$} & {$[0.00]$} & {$[0.00]$} \\
\hline \multicolumn{4}{|l|}{ (3) Tobin's $q$} \\
\hline IAS & $\begin{array}{l}-36.02 * * * \\
(-12.12)\end{array}$ & $\begin{array}{l}-5.94 \\
(-1.34)\end{array}$ & $\begin{array}{l}-17.24 * * * \\
(-3.99)\end{array}$ \\
\hline Serious Adopters & $\begin{array}{l}57.17^{* * *} \\
(11.64)\end{array}$ & $\begin{array}{l}10.12 \\
(1.55)\end{array}$ & $\begin{array}{l}20.73^{* * *} \\
(3.34)\end{array}$ \\
\hline IAS + Serious $=0[p$-value $]$ & {$[0.00]$} & [0.43] & {$[0.47]$} \\
\hline \multicolumn{4}{|c|}{ Panel B: Alternative Accounting Standards Classifications (Price Impact as Dependent Variable) } \\
\hline $\begin{array}{l}\text { (4) Voluntary IAS and U.S. GAAP Adoption } \\
\text { IAS/U.S. GAAP }\end{array}$ & $\begin{array}{l}16.31^{* * *} \\
(3.53)\end{array}$ & $\begin{array}{c}5.45 \\
(1.10)\end{array}$ & $\begin{array}{l}20.51 * * * \\
(4.11)\end{array}$ \\
\hline Serious Adopters & $\begin{array}{l}-48.19 * * * \\
(-7.42)\end{array}$ & $\begin{array}{l}-18.76^{* * *} \\
(-2.95)\end{array}$ & $\begin{array}{l}-39.72 * * * \\
(-6.45)\end{array}$ \\
\hline IAS/U.S. GAAP + Serious $=0$ [p-value $]$ & {$[0.00]$} & {$[0.01]$} & {$[0.00]$} \\
\hline \multicolumn{4}{|l|}{ (5) Voluntary U.S. GAAP Adoption } \\
\hline U.S. GAAP & $\begin{array}{l}11.03 \\
(0.83)\end{array}$ & $\begin{array}{c}-6.07 \\
(-0.39)\end{array}$ & $\begin{array}{l}18.02 \\
(1.31)\end{array}$ \\
\hline Serious Adopters & $\begin{array}{l}-56.48 * * * \\
(-2.97)\end{array}$ & $\begin{array}{l}-16.90 \\
(-0.94)\end{array}$ & $\begin{array}{l}-42.14 * * \\
(-2.56)\end{array}$ \\
\hline U.S. GAAP + Serious $=0$ [p-value $]$ & {$[0.00]$} & {$[0.05]$} & {$[0.04]$} \\
\hline \multicolumn{4}{|c|}{ Panel C: Alternative Sample Compositions (Price Impact as Dependent Variable) } \\
\hline \multicolumn{4}{|l|}{ (6) Exclude Firms from the U.K. and Canada } \\
\hline IAS & $\begin{array}{l}13.54 * * * \\
(2.79)\end{array}$ & $\begin{array}{c}1.17 \\
(0.23)\end{array}$ & $\begin{array}{l}14.82^{* * *} \\
(2.79)\end{array}$ \\
\hline Serious Adopters & $\begin{array}{l}-46.64 * * * \\
(-6.77)\end{array}$ & $\begin{array}{l}-16.19^{* *} \\
(-2.38)\end{array}$ & $\begin{array}{l}-38.22 * * * \\
(-5.74)\end{array}$ \\
\hline IAS + Serious $=0[p$-value $]$ & {$[0.00]$} & {$[0.00]$} & {$[0.00]$} \\
\hline \multicolumn{4}{|l|}{ (7) IAS Firms only } \\
\hline IAS & $\begin{array}{c}4.63 \\
(0.82)\end{array}$ & $\begin{array}{c}-4.91 \\
(-0.87)\end{array}$ & $\begin{array}{c}2.70 \\
(0.46)\end{array}$ \\
\hline Serious Adopters & $\begin{array}{l}-44.69 * * * \\
(-6.62)\end{array}$ & $\begin{array}{l}-11.70^{*} \\
(-1.83)\end{array}$ & $\begin{array}{l}-28.94 * * * \\
(-4.40)\end{array}$ \\
\hline IAS + Serious $=0$ [p-value $]$ & {$[0.00]$} & {$[0.01]$} & {$[0.00]$} \\
\hline \multicolumn{4}{|c|}{ Panel D: Alternative Model Specifications (Price Impact as Dependent Variable) } \\
\hline \multicolumn{4}{|c|}{ (8) Firm-Fixed Effects instead of Country-and Industry-Fixed Effects } \\
\hline IAS & $\begin{array}{l}20.19 * * \\
(2.41)\end{array}$ & $\begin{array}{l}-1.98 \\
(-0.24)\end{array}$ & $\begin{array}{l}-2.79 \\
(-0.29)\end{array}$ \\
\hline Serious Adopters & $\begin{array}{l}-82.36 * * * \\
(-6.71)\end{array}$ & $\begin{array}{c}-24.08^{*} \\
(-1.84)\end{array}$ & $\begin{array}{l}-20.75 \\
(-1.62)\end{array}$ \\
\hline IAS + Serious $=0[p$-value $]$ & {$[0.00]$} & {$[0.01]$} & {$[0.00]$} \\
\hline
\end{tabular}




\section{TABLE 8-Continued}

The sample comprises firm-year observations from up to 30 countries with voluntary IAS adoptions between 1990 and 2005 (see Table 1). The table reports only the OLS coefficients (t-statistics, clustered by firm) of the IAS and Serious Adopters (U.S. GAAP and Serious Adopters) variables, but the full set of controls and fixed effects is included (see Table 6). It also reports p-values [in brackets] from an F-test indicating joint statistical significance of the two variables. We show results for the serious and label adopters using each of the three Reporting Variables to partition the IAS (U.S. GAAP) observations. In Panel A, we examine the following alternative dependent variables: Total Trading Costs is a yearly estimate of total roundtrip transaction costs (i.e., bid-ask spreads, commissions, and implicit costs such as short-sale constraints or taxes) inferred from the time-series of daily security and aggregate market returns (see Lesmond, Ogden, and Trzcinka [1999]). Zero Returns is the proportion of trading days with zero daily stock returns out of all potential trading days in a given year. Tobin's $q$ equals (total assets - book value of equity + market value of equity)/total assets. The total trading costs and zero returns specifications are the same as for price impact. For Tobin's q we use the log of total assets, financial leverage, asset growth (computed as the one-year percentage change in total assets), and industry q (equal to the yearly median q in a given industry) as continuous control variables. In the remaining panels, we use Price Impact as the dependent variable. In Panel B, we report results for two alternative accounting standards classifications. First, we create a combined IAS and U.S. GAAP variable (based on our augmented Worldscope accounting standards classification), and split the firms that switch from local GAAP to either IAS or U.S. GAAP into serious and label adopters. Second, we focus on the voluntary U.S. GAAP adopters and partition them into serious and label adopters (while controlling for IAS reporting in the regression). In Panel C, we report results for alternative sample compositions. First, we exclude firms from the U.K. and Canada from the sample. Second, we limit the analysis to firms that at some point during the sample period reported under IAS. In Panel D, we replace the country- and industry-fixed effects with firm-fixed effects. For expositional purposes we multiply all coefficients by $100 . * * * * *$, and $*$ indicate statistical significance at the $1 \%, 5 \%$, and $10 \%$ levels (two-tailed). 
TABLE A1

Accounting Standards Classifications Based on Different Data Sources

Panel A: Coding Based on Worldscope (WS) “Accounting Standards Followed” (Field 07536)

WS Code WS Description

Coding

for Analyses

We code firm-year observations as IAS if one of the following cases applies:

IAS

$02 \quad$ International standards

06 International standards and some EU guidelines

08 Local standards with EU and IASC guidelines

12 International standards - inconsistency problems

16 International standards and some EU guidelines - inconsistency problems

18 Local standards with some IASC guidelines

19 Local standards with OECD and IASC guidelines

23 IFRS

We code firm-year observations as U.S. GAAP if one of the following cases applies:

U.S. GAAP

03 U.S. standards (GAAP)

13 US standards - inconsistency problems

20 US GAAP reclassified from local standards

We code firm-year observations as local if one of the following cases applies:

Local

$01 \quad$ Local standards

$05 \quad$ EU standards

$07 \quad$ Specific standards set by the group

$09 \quad$ Not disclosed

10 Local standards with some EU guidelines

11 Local standards - inconsistency problems

14 Commonwealth standards - inconsistency problems

15 EEC standards - inconsistency problems

17 Local standards with some OECD guidelines

21 Local standards with a certain reclassification for foreign companies

$22 \quad$ Other

Panel B: Coding Based on Global Vantage (GV) "Accounting Standard" (Field ASTD)

GV Code GV Description

Coding

We code firm-year observations as IAS if one of the following cases applies:

for Analyses

DA Domestic standards generally in accordance with IASC and OECD guidelines

DI Domestic standards generally in accordance with IASC guidelines

DT Domestic standards in accordance with principles generally accepted in the United

States and generally in accordance with IASC and OECD guidelines

We code firm-year observations as U.S. GAAP if one of the following cases applies:

U.S. GAAP

DU Domestic standards in accordance with principles generally accepted in the U.S.

MU Modified United States' standards (Japanese companies' financial statements translated into English)

US United States' standards

We code firm-year observations as local if one of the following cases applies:

Local

DD Domestic standards for parents and domestic subsidiaries. Native country or United

States' standards for overseas subsidiaries

DO Domestic standards generally in accordance with OECD guidelines

DR Accounts reclassified to show allowance for doubtful accounts and/or accumulated depreciation as a reduction of assets rather than liabilities

DS Domestic standards

MI Accounts reclassified by SPCS to combine separate life insurance and non-life insurance accounts

LJ Combination DR and MI 
TABLE A1-Continued

\section{Panel C: Hand-Coded Classification Based on Firms' Annual Reports}

Description

Coding

We code firm-year observations as IAS if one of the following cases applies:

for Analyses

(1) Notes to consolidated financial statements refer to IAS/IFRS only

(2) Annual report has two separate sections with two full sets of consolidated financial statements (balance sheet, income statement, statement of cash flows), one set under local GAAP, and one set under IAS/IFRS (Parallel Reporting)

(3) Notes to consolidated financial statements refer to IAS/IFRS in the first place, but also refer to compliance with local GAAP

(4) Notes to consolidated financial statements refer to local GAAP in the first place, but also refer to compliance with IAS/IFRS

(5) Notes to consolidated financial statements refer to full compliance with local GAAP, but also to application of IAS/IFRS if local GAAP is silent about a reporting issue (Dual Reporting)

(6) Notes to consolidated financial statements refer to full application local GAAP, but there is also a reconciliation of net income and/or shareholders' equity to IAS/IFRS in a separate section of the annual report (Reconciliation)

We code firm-year observations as U.S. GAAP if one of the following cases applies:

U.S. GAAP

(1) Notes to consolidated financial statements refer to U.S. GAAP only

(2) Annual report has two separate sections with two full sets of consolidated financial statements (balance sheet, income statement, statement of cash flows), one set under local GAAP, and one set under U.S. GAAP (Parallel Reporting)

(3) Notes to consolidated financial statements refer to U.S. GAAP in the first place, but also refer to compliance with local GAAP

(4) Notes to consolidated financial statements refer to local GAAP in the first place, but also refer to compliance with U.S. GAAP

(5) Notes to consolidated financial statements refer to full compliance with local GAAP, but also to application of U.S. GAAP if local GAAP is silent about a reporting issue (Dual Reporting)

(6) Notes to consolidated financial statements refer to full application local GAAP, but there is also a reconciliation of net income and/or shareholders' equity to U.S. GAAP in a separate section of the annual report (Reconciliation)

We code firm-year observations as local if one of the following cases applies:

Local

(1) Notes to consolidated financial statements refer to local GAAP only

(2) Notes to consolidated financial statements refer to local GAAP only, but selected individual IAS/IFRS or U.S. GAAP standards are applied on specific reporting issues (e.g. Leasing IAS 17, Segment Reporting SFAS 131)

The table describes the assignment of firm-year observations to the reporting categories IAS, U.S. GAAP or Local GAAP using three different accounting standards classifications. The first two are based on Worldscope (Panel A) and Global Vantage (Panel B), as retrieved in May 2006. The third classification is hand-coded and based on firms' annual reports collected through Thomson Research (Panel C). In our main analyses, we use an augmented classification that combines information from all three classifications. 
TABLE A2

Comparison of Accounting Standards Classifications by Data Source (For Sample Used in Main Analyses)

Panel A: Worldscope versus Global Vantage Classifications

\begin{tabular}{|c|c|c|c|c|c|c|c|c|}
\hline \multirow{4}{*}{$\begin{array}{l}\text { Global Vantage } \\
\text { Classification }\end{array}$} & \multicolumn{4}{|c|}{ Comprehensive Coding for IAS } & \multicolumn{4}{|c|}{ Stricter Coding for IAS } \\
\hline & \multirow{2}{*}{\multicolumn{4}{|c|}{$\begin{array}{l}\text { Worldscope Classification } \\
\text { U.S. }\end{array}$}} & \multirow{2}{*}{\multicolumn{4}{|c|}{$\begin{array}{l}\text { Worldscope Classification } \\
\text { U.S. }\end{array}$}} \\
\hline & & & & & & & & \\
\hline & $I A S$ & $G A A P$ & Local & Total & $I A S$ & $G A A P$ & Local & Total \\
\hline \multirow[t]{2}{*}{$I A S$} & 2,001 & 7 & 844 & 2,852 & 1,800 & 7 & 921 & 2,728 \\
\hline & $2.9 \%$ & $0.0 \%$ & $1.2 \%$ & $4.1 \%$ & $2.6 \%$ & $0.0 \%$ & $1.3 \%$ & $3.9 \%$ \\
\hline \multirow[t]{2}{*}{ U.S. GAAP } & 26 & 606 & 178 & 810 & 1 & 481 & 78 & 560 \\
\hline & $0.0 \%$ & $0.7 \%$ & $0.5 \%$ & $1.2 \%$ & $0.0 \%$ & $0.7 \%$ & $0.1 \%$ & $0.8 \%$ \\
\hline \multirow[t]{2}{*}{ Local } & 1,658 & 218 & 45,273 & 47,149 & 737 & 332 & 46,454 & 47,523 \\
\hline & $2.4 \%$ & $0.5 \%$ & $64.9 \%$ & $67.8 \%$ & $1.1 \%$ & $0.5 \%$ & $66.8 \%$ & $68.4 \%$ \\
\hline \multirow[t]{2}{*}{ Not covered } & 662 & 252 & 17,803 & 18,717 & 447 & 252 & 18,018 & 18,717 \\
\hline & $0.9 \%$ & $0.4 \%$ & $25.6 \%$ & $26.9 \%$ & $0.6 \%$ & $0.4 \%$ & $25.9 \%$ & $26.9 \%$ \\
\hline \multirow[t]{2}{*}{ Total } & 4,347 & 1,083 & 64,098 & 69,528 & 2,985 & 1,072 & 65,471 & 69,528 \\
\hline & $6.3 \%$ & $1.6 \%$ & $92.2 \%$ & $100.0 \%$ & $4.3 \%$ & $1.5 \%$ & $94.2 \%$ & $100.0 \%$ \\
\hline
\end{tabular}

Panel B: Hand-Coded Classification versus Worldscope and Global Vantage Classifications

\begin{tabular}{|c|c|c|c|c|c|c|c|c|c|c|}
\hline \multirow{3}{*}{$\begin{array}{l}\text { Hand-coded } \\
\text { Classification }\end{array}$} & \multicolumn{5}{|c|}{ Worldscope Classification } & \multicolumn{5}{|c|}{ Global Vantage Classification } \\
\hline & & U.S. & & Not & & & U.S. & & Not & \\
\hline & $I A S$ & $G A A P$ & Local & covered & Total & $I A S$ & GAAP & Local & covered & Total \\
\hline \multirow[t]{2}{*}{$I A S$} & 2,912 & 66 & 725 & n.a. & 3,703 & 2,150 & 6 & 1,009 & 538 & 3,703 \\
\hline & $4.2 \%$ & $0.1 \%$ & $1.0 \%$ & & $5.3 \%$ & $3.1 \%$ & $0.0 \%$ & $1.5 \%$ & $0.8 \%$ & $5.3 \%$ \\
\hline \multirow[t]{2}{*}{ U.S. GAAP } & 45 & 787 & 377 & n.a. & 1,209 & 20 & 537 & 406 & 246 & 1,209 \\
\hline & $0.1 \%$ & $1.1 \%$ & $0.5 \%$ & & $1.7 \%$ & $0.0 \%$ & $0.8 \%$ & $0.6 \%$ & $0.4 \%$ & $1.7 \%$ \\
\hline \multirow[t]{2}{*}{ Local } & 923 & 66 & 3,288 & n.a. & 4,277 & 399 & 69 & 2,981 & 828 & 4,277 \\
\hline & $1.3 \%$ & $0.1 \%$ & $4.7 \%$ & & $6.2 \%$ & $0.6 \%$ & $0.1 \%$ & $4.3 \%$ & $1.2 \%$ & $6.2 \%$ \\
\hline \multirow{2}{*}{$\begin{array}{l}\text { No annual } \\
\text { report data }\end{array}$} & 467 & 223 & 59,649 & n.a. & 60,339 & 283 & 198 & 42,753 & 17,105 & 60,339 \\
\hline & $0.7 \%$ & $0.3 \%$ & $85.8 \%$ & & $86.8 \%$ & $0.4 \%$ & $0.3 \%$ & $61.5 \%$ & $24.6 \%$ & $86.8 \%$ \\
\hline \multirow[t]{2}{*}{ Total } & 4,347 & 1,083 & 64,098 & n.a. & 69,528 & 2,852 & 810 & 47,149 & 18,717 & 69,528 \\
\hline & $6.3 \%$ & $1.6 \%$ & $92.2 \%$ & & $100.0 \%$ & $4.1 \%$ & $1.2 \%$ & $67.8 \%$ & $26.9 \%$ & $100.0 \%$ \\
\hline
\end{tabular}

Panel C: Pearson's Correlation Coefficients of IAS Classifications across Data Sources

\begin{tabular}{lcc} 
& $\begin{array}{c}\text { Worldscope } \\
\text { Classification }\end{array}$ & $\begin{array}{c}\text { Global Vantage } \\
\text { Classification }\end{array}$ \\
\hline Hand-coded Classification & 0.609 & 0.605 \\
p-values & $(0.00)$ & $(0.00)$ \\
$\mathrm{N}$ & 9,176 & 7,570 \\
Worldscope Classification & & 0.593 \\
p-values & & $(0.00)$ \\
$\mathrm{N}$ & & 50,775 \\
\hline
\end{tabular}

The table presents the number of observations and percentages across different accounting standards classifications for our base sample comprising 69,528 firm-year observations from 30 countries between 1990 and 2005 (see Table 1). In Panel A, we compare IAS, U.S. GAAP, or local GAAP firm-years based on the accounting standards classification in Worldscope and Global Vantage. The left-hand side of the panel applies the coding scheme as outlined in Table A1. On the right-hand side we use a stricter coding for IAS observations consisting of Worldscope categories 02 ("International standards") and 23 ("IFRS") together with Global Vantage category DI ("Domestic standards generally in accordance with IASC guidelines"). In Panel B, we compare our own classification based on an extensive manual review of firms' annual reports (see Table A1, Panel C) with the coding based on Worldscope and Global Vantage. Panel C reports the respective Pearson correlations across the three data sources. 
TABLE A3

Comparison of Accounting Standards Classifications by Country

\begin{tabular}{|c|c|c|c|c|c|c|c|c|c|c|c|c|c|c|c|}
\hline \multirow[b]{3}{*}{ Country } & & \multicolumn{4}{|c|}{$\begin{array}{l}\text { Worldscope } \\
\text { Classification }\end{array}$} & \multicolumn{5}{|c|}{$\begin{array}{l}\text { Global Vantage } \\
\text { Classification }\end{array}$} & \multicolumn{5}{|c|}{$\begin{array}{l}\text { Hand-Coded Classification } \\
\text { plus Local GAAP Firms }\end{array}$} \\
\hline & & \multicolumn{2}{|c|}{ IAS } & \multicolumn{2}{|c|}{ U.S. GAAP } & \multicolumn{3}{|c|}{ IAS } & \multicolumn{2}{|c|}{ U.S. GAAP } & \multicolumn{3}{|c|}{ IAS } & \multicolumn{2}{|c|}{ U.S. GAAP } \\
\hline & $\mathrm{n}$ & $\mathrm{n}$ & $\%$ & $\mathrm{n}$ & $\%$ & $\mathrm{n}$ & $\mathrm{n}$ & $\%$ & $\mathrm{n}$ & $\%$ & $\mathrm{n}$ & $\mathrm{n}$ & $\%$ & $\mathrm{n}$ & $\%$ \\
\hline Argentina & 899 & 3 & 0.3 & 10 & 1.1 & 361 & 0 & 0.0 & 6 & 1.7 & 337 & 3 & 0.9 & 7 & 2.1 \\
\hline Australia & 12,371 & 142 & 1.1 & 22 & 0.2 & 4,917 & 17 & 0.3 & 8 & 0.2 & 4,044 & 134 & 3.3 & 23 & 0.6 \\
\hline Austria & 2,027 & 332 & 16.4 & 44 & 2.2 & 1,183 & 282 & 23.8 & 38 & 3.2 & 1,245 & 343 & 27.6 & 43 & 3.5 \\
\hline Belgium & 3,022 & 187 & 6.2 & 39 & 1.3 & 1,636 & 135 & 8.3 & 48 & 2.9 & 1,341 & 179 & 13.3 & 55 & 4.1 \\
\hline Bermuda & 315 & 50 & 15.9 & 120 & 38.1 & 4,422 & 268 & 6.1 & 86 & 1.9 & 220 & 51 & 23.2 & 105 & 47.7 \\
\hline Brazil & 3,673 & 2 & 0.1 & 6 & 0.2 & 1,698 & 0 & 0.0 & 2 & 0.1 & 1,374 & 1 & 0.1 & 1 & 0.1 \\
\hline Canada & 17,502 & 87 & 0.5 & 418 & 2.4 & 9,641 & 13 & 0.1 & 24 & 0.2 & 7,669 & 40 & 0.5 & 529 & 6.9 \\
\hline Chile & 2,063 & 1 & 0.0 & 2 & 0.1 & 1,106 & 0 & 0.0 & 1 & 0.1 & 998 & 0 & 0.0 & 0 & 0.0 \\
\hline China & 10,598 & 1,144 & 10.8 & 108 & 1.0 & 14,066 & 224 & 1.6 & 4 & 0.0 & 8,515 & 1,157 & 13.6 & 54 & 0.6 \\
\hline Colombia & 527 & 0 & 0.0 & 0 & 0.0 & 265 & 0 & 0.0 & 0 & 0.0 & 197 & 0 & 0.0 & 0 & 0.0 \\
\hline Czech Republic & 470 & 90 & 19.1 & 0 & 0.0 & 194 & 73 & 37.6 & 0 & 0.0 & 206 & 68 & 33.0 & 0 & 0.0 \\
\hline Denmark & 3,854 & 141 & 3.7 & 14 & 0.4 & 2,086 & 118 & 5.7 & 0 & 0.0 & 1,853 & 155 & 8.4 & 23 & 1.2 \\
\hline Egypt & 145 & 2 & 1.4 & 0 & 0.0 & 0 & 0 & 0.0 & 0 & 0.0 & 0 & 0 & 0.0 & 0 & 0.0 \\
\hline Finland & 2,697 & 70 & 2.6 & 0 & 0.0 & 1,359 & 95 & 7.0 & 3 & 0.2 & 1,298 & 79 & 6.1 & 8 & 0.6 \\
\hline France & 15,533 & 961 & 6.2 & 182 & 1.2 & 8,100 & 591 & 7.3 & 200 & 2.5 & 5,528 & 347 & 6.3 & 197 & 3.6 \\
\hline Germany & 15,744 & 1,685 & 10.7 & 714 & 4.5 & 8,212 & 1,632 & 19.9 & 841 & 10.2 & 7,681 & 1,723 & 22.4 & 679 & 8.8 \\
\hline Greece & 3,133 & 43 & 1.4 & 29 & 0.9 & 742 & 38 & 5.1 & 16 & 2.2 & 629 & 41 & 6.5 & 23 & 3.7 \\
\hline Hong Kong & 8,855 & 200 & 2.3 & 59 & 0.7 & 2,374 & 13 & 0.5 & 2 & 0.1 & 5,793 & 163 & 2.8 & 33 & 0.6 \\
\hline Hungary & 380 & 192 & 50.5 & 7 & 1.8 & 182 & 132 & 72.5 & 8 & 4.4 & 225 & 154 & 68.4 & 0 & 0.0 \\
\hline India & 4,547 & 8 & 0.2 & 17 & 0.4 & 2,644 & 4 & 0.2 & 6 & 0.2 & 2,010 & 0 & 0.0 & 18 & 0.9 \\
\hline Indonesia & 3,268 & 1 & 0.0 & 0 & 0.0 & 2,541 & 0 & 0.0 & 7 & 0.3 & 2,204 & 0 & 0.0 & 7 & 0.3 \\
\hline Ireland & 1,498 & 40 & 2.7 & 30 & 2.0 & 784 & 1 & 0.1 & 6 & 0.8 & 660 & 0 & 0.0 & 27 & 4.1 \\
\hline Israel & 1,264 & 45 & 3.6 & 361 & 28.6 & 646 & 21 & 3.3 & 112 & 17.3 & 786 & 49 & 6.2 & 411 & 52.3 \\
\hline Italy & 5,544 & 4,364 & 78.7 & 8 & 0.1 & 2,944 & 6 & 0.2 & 18 & 0.6 & 3,236 & 813 & 25.1 & 34 & 1.1 \\
\hline Japan & 56,817 & 133 & 0.2 & 944 & 1.7 & 45,184 & 5 & 0.0 & 348 & 0.8 & 36,667 & 0 & 0.0 & 637 & 1.7 \\
\hline Korea (South) & 8,566 & 10 & 0.1 & 5 & 0.1 & 2,146 & 0 & 0.0 & 2 & 0.1 & 1,987 & 0 & 0.0 & 5 & 0.3 \\
\hline Luxembourg & 484 & 99 & 20.5 & 50 & 10.3 & 305 & 93 & 30.5 & 39 & 12.8 & 191 & 107 & 56.0 & 25 & 13.1 \\
\hline Malaysia & 9,123 & 24 & 0.3 & 0 & 0.0 & 8,167 & 34 & 0.4 & 0 & 0.0 & 6,718 & 2 & 0.0 & 0 & 0.0 \\
\hline Mexico & 1,993 & 7 & 0.4 & 8 & 0.4 & 977 & 8 & 0.8 & 3 & 0.3 & 862 & 10 & 1.2 & 15 & 1.7 \\
\hline Morocco & 140 & 1 & 0.7 & 0 & 0.0 & 0 & 0 & 0.0 & 0 & 0.0 & 0 & 0 & 0.0 & 0 & 0.0 \\
\hline
\end{tabular}


TABLE A3-Continued

\begin{tabular}{|c|c|c|c|c|c|c|c|c|c|c|c|c|c|c|c|}
\hline \multirow[b]{3}{*}{ Country } & & \multicolumn{4}{|c|}{$\begin{array}{l}\text { Worldscope } \\
\text { Classification }\end{array}$} & \multicolumn{5}{|c|}{$\begin{array}{c}\text { Global Vantage } \\
\text { Classification }\end{array}$} & \multicolumn{5}{|c|}{$\begin{array}{c}\text { Hand-Coded Classification } \\
\text { plus Local GAAP Firms }\end{array}$} \\
\hline & & \multicolumn{2}{|c|}{ IAS } & \multicolumn{2}{|c|}{ U.S. GAAP } & \multirow[b]{2}{*}{$\mathrm{n}$} & \multicolumn{2}{|c|}{ IAS } & \multicolumn{2}{|c|}{ U.S. GAAP } & \multirow[b]{2}{*}{$\mathrm{n}$} & \multicolumn{2}{|c|}{ IAS } & \multicolumn{2}{|c|}{ U.S. GAAP } \\
\hline & $\mathrm{n}$ & $\mathrm{n}$ & $\%$ & $\mathrm{n}$ & $\%$ & & $\mathrm{n}$ & $\%$ & $\mathrm{n}$ & $\%$ & & $\mathrm{n}$ & $\%$ & $\mathrm{n}$ & $\%$ \\
\hline The Netherlands & 4,295 & 185 & 4.3 & 232 & 5.4 & 2,533 & 95 & 3.8 & 162 & 6.4 & 2,151 & 131 & 6.1 & 192 & 8.9 \\
\hline New Zealand & 1,463 & 31 & 2.1 & 0 & 0.0 & 756 & 12 & 1.6 & 25 & 3.3 & 629 & 6 & 1.0 & 28 & 4.5 \\
\hline Norway & 3,120 & 35 & 1.1 & 63 & 2.0 & 1,722 & 23 & 1.3 & 27 & 1.6 & 1,411 & 30 & 2.1 & 67 & 4.7 \\
\hline Pakistan & 1,017 & 16 & 1.6 & 0 & 0.0 & 454 & 12 & 2.6 & 0 & 0.0 & 432 & 68 & 15.7 & 0 & 0.0 \\
\hline Peru & 812 & 10 & 1.2 & 4 & 0.5 & 0 & 0 & 0.0 & 0 & 0.0 & 283 & 149 & 52.7 & 6 & 2.1 \\
\hline Philippines & 2,117 & 2 & 0.1 & 18 & 0.9 & 1,575 & 134 & 8.5 & 10 & 0.6 & 789 & 7 & 0.9 & 21 & 2.7 \\
\hline Poland & 880 & 82 & 9.3 & 5 & 0.6 & 362 & 59 & 16.3 & 0 & 0.0 & 243 & 56 & 23.0 & 5 & 2.1 \\
\hline Portugal & 1,368 & 33 & 2.4 & 1 & 0.1 & 551 & 21 & 3.8 & 0 & 0.0 & 351 & 36 & 10.3 & 0 & 0.0 \\
\hline Russian Federation & 387 & 113 & 29.2 & 81 & 20.9 & 150 & 60 & 40.0 & 51 & 34.0 & 220 & 91 & 41.4 & 57 & 25.9 \\
\hline Singapore & 5,465 & 147 & 2.7 & 35 & 0.6 & 4,410 & 17 & 0.4 & 22 & 0.5 & 3,996 & 139 & 3.5 & 39 & 1.0 \\
\hline South Africa & 5,936 & 75 & 1.3 & 4 & 0.1 & 1,740 & 149 & 8.6 & 5 & 0.3 & 1,452 & 162 & 11.2 & 4 & 0.3 \\
\hline Spain & 3,313 & 22 & 0.7 & 7 & 0.2 & 1,906 & 8 & 0.4 & 5 & 0.3 & 1,556 & 6 & 0.4 & 5 & 0.3 \\
\hline Sri Lanka & 256 & 0 & 0.0 & 0 & 0.0 & 0 & 0 & 0.0 & 0 & 0.0 & 0 & 0 & 0.0 & 0 & 0.0 \\
\hline Sweden & 5,376 & 174 & 3.2 & 0 & 0.0 & 3,099 & 132 & 4.3 & 22 & 0.7 & 2,651 & 93 & 3.5 & 14 & 0.5 \\
\hline Switzerland & 4,863 & 1,515 & 31.2 & 130 & 2.7 & 3,113 & 1,294 & 41.6 & 105 & 3.4 & 3,207 & 1,356 & 42.3 & 117 & 3.6 \\
\hline Taiwan & 8,873 & 1 & 0.0 & 11 & 0.1 & 2,477 & 0 & 0.0 & 0 & 0.0 & 2,249 & 0 & 0.0 & 15 & 0.7 \\
\hline Thailand & 5,033 & 5 & 0.1 & 0 & 0.0 & 4,140 & 9 & 0.2 & 1 & 0.0 & 3,530 & 4 & 0.1 & 0 & 0.0 \\
\hline Turkey & 1,921 & 255 & 13.3 & 2 & 0.1 & 469 & 156 & 33.3 & 10 & 2.1 & 945 & 276 & 29.2 & 6 & 0.6 \\
\hline United Kingdom & 37,700 & 233 & 0.6 & 83 & 0.2 & 18,228 & 56 & 0.3 & 50 & 0.3 & 15,669 & 170 & 1.1 & 53 & 0.3 \\
\hline Venezuela & 454 & 3 & 0.7 & 17 & 3.7 & 0 & 0 & 0.0 & 0 & 0.0 & 0 & 0 & 0.0 & 0 & 0.0 \\
\hline Total & 291,701 & 13,001 & 4.5 & 3,890 & 1.3 & 178,459 & 6,227 & 3.5 & 2,345 & 1.3 & 146,238 & 8,399 & 5.7 & 3,588 & 2.5 \\
\hline
\end{tabular}

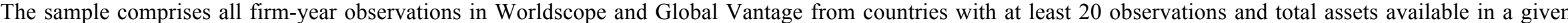

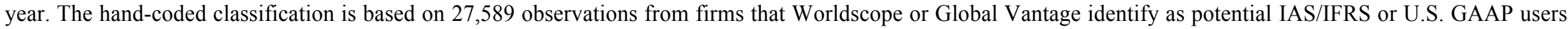

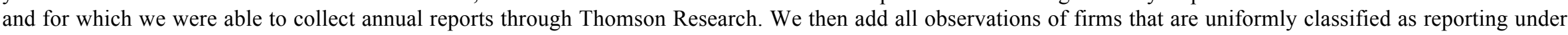

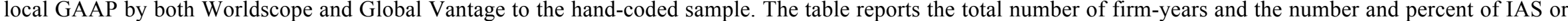
U.S. GAAP observations, using the three accounting standards classifications outlined in Table A1. 
TABLE A4

IAS Adoption Patterns and Identification of IAS Switch Years

Description of IAS Adoption Patterns over Time

Unique Firm-

Firms Years $\%$

\section{Panel A: Firms with IAS Switch Year}

In the following (stylized) cases, we can identify a switch year to IAS/IFRS reporting, and hence classify firms as serious or label IAS adopters for our analyses.

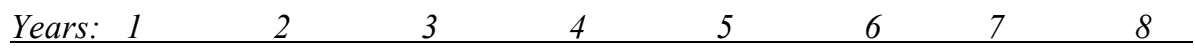

(1) Firms switching from local GAAP to IAS

Local Local Local Local IAS IAS IAS IAS

(2) Firms switching from local GAAP to IAS, and then back to local GAAP

Local Local IAS IAS IAS LAS Local Local

(3) Firms switching from local GAAP to IAS, back to local GAAP, and then for a second time to IAS
Local Local
IAS
IAS
Local
Local IAS
IAS

(4) Firms switching twice from local GAAP to IAS, and back to local GAAP
Local IAS
IAS Local Local
IAS IAS Local

(5) Firms switching from IAS to local GAAP, and then back to IAS
IAS
IAS
Local Local Local
IAS IAS

\section{IAS}

(6) Firms switching from IAS to local GAAP, back to IAS, and then for a second time to local GAAP

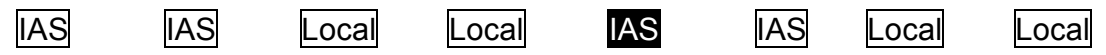

(7) Firms switching from local GAAP to IAS, and then to U.S. GAAP
Local
Local Local
IAS IAS
IAS U.S.
U.S.

696

19

71

0.1

Panel B: Firms without IAS Switch Year

In the following (stylized) cases, we are unable to identify a switch year to IAS/IFRS reporting, and hence exclude the firms from the serious versus label IAS partitions.

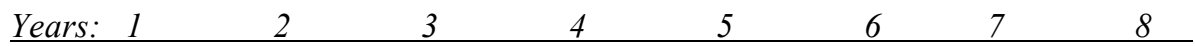

(1) Firms reporting under IAS during the entire time period

\begin{tabular}{lllll}
\hline IAS IAS IAS IAS IAS IAS IAS IAS &
\end{tabular}

(2) Firms switching from IAS to local GAAP

IAS IAS IAS IAS Local Local Local Local

(3) Firms switching from local GAAP to U.S. GAAP, and then to IAS
Local Loca
U.S. U.S.
U.S. IAS IAS
IAS

(4) Firms switching from U.S. GAAP to IAS
U.S.
U.S.
U.S.
U.S.
IAS IAS IAS
IAS

(5) Firms reporting under local GAAP during the entire time period

Local Local Local Local Local Local Local Local

10,756

61,465

88.4

(6) Other (e.g., more than two switches; switches to other foreign GAAP)

Total

12,171

69,528

100.0

The table reports the number of unique firms, and the number and percentage of firm-years across various IAS adoption patterns for our base sample comprising 69,528 firm-year observations from 30 countries between 1990 and 2005 (see Table 1). We create a panel of firms' accounting standards over time based on the "accounting standards followed" field in Worldscope (field 07536), and then adjusted the coding for contradictory information from an extensive review of firms' annual reports. We manually check that the augmenting process does not introduce artificial IAS switch years. We require a switch year (denoted by IAS in Panel A) for IAS adopting firms to be included in the serious versus label analyses. For firms with two IAS switch years, we utilize the second switch year in our analyses because our manual review found those to be more reliable. In this case, we set the earlier IAS firm-year observations to missing. 